\title{
Impact of Land-Use Change on Atmospheric Environment Using Refined Land Surface Properties in the Pearl River Delta, China
}

\author{
Anqi Lai, ${ }^{1}$ Yiming Liu, ${ }^{1}$ Xiaoyang Chen, ${ }^{1}$ Ming Chang, ${ }^{1}$ Qi Fan, \\ Pakwai Chan, ${ }^{2}$ Xuemei Wang, ${ }^{1}$ and Jianing Dai ${ }^{1}$ \\ ${ }^{1}$ School of Atmospheric Science, Sun Yat-sen University, Guangzhou 510275, China \\ ${ }^{2}$ Hong Kong Observatory, Tsim Sha Tsui 999077, Hong Kong \\ Correspondence should be addressed to Qi Fan; eesfa@mail.sysu.edu.cn
}

Received 14 June 2016; Revised 16 October 2016; Accepted 8 November 2016

Academic Editor: Mario M. Miglietta

Copyright (c) 2016 Anqi Lai et al. This is an open access article distributed under the Creative Commons Attribution License, which permits unrestricted use, distribution, and reproduction in any medium, provided the original work is properly cited.

\begin{abstract}
We replaced the outdated land-use of the Weather Research and Forecasting-Chemistry (WRF-Chem) model with a refined dataset, the Global Land Cover 2009 (GLC2009) dataset, to investigate the impact of land-use change on the regional atmospheric environment in the Pearl River Delta (PRD) region. Simulations of two months in 2014 (January and July) showed that landuse change increased the monthly averaged $2 \mathrm{~m}$ temperature by $0.24^{\circ} \mathrm{C}$ and $0.27^{\circ} \mathrm{C}$ in January and July, respectively. The relative humidity decreased by $2.02 \%$ and $2.23 \%$ in January and July, respectively. Due to the increase in ground roughness, the monthly averaged wind speed in January and July decreased by $0.19 \mathrm{~m} / \mathrm{s}$ and $0.16 \mathrm{~m} / \mathrm{s}$. The planetary boundary layer height increased throughout the day and with larger relative increase during the nighttime. These subtle changes caused by land-use resulted in discernable changes in pollutant concentrations. Monthly averaged surface $\mathrm{O}_{3}$ concentration increased by $0.93 \mu \mathrm{g} / \mathrm{m}^{3}$ and $1.61 \mu \mathrm{g} / \mathrm{m}^{3}$ in January and July, while $\mathrm{PM}_{2.5}$ concentration decreased by $1.58 \mu \mathrm{g} / \mathrm{m}^{3}$ and $3.76 \mu \mathrm{g} / \mathrm{m}^{3}$, and the changes in pollutant concentrations were more noticeable during the nighttime. Overall, the impacts of land-use change on the atmospheric environment are obvious throughout the PRD region, especially in the urbanized areas.
\end{abstract}

\section{Introduction}

The changes of land-use types significantly influence the dynamic and thermal properties of underlying surfaces, such as surface waterproofness, roughness length, albedo, and heat flux. These in turn influence the energy exchange process and matter and momentum of the atmosphere-surface system, thereby affecting the atmospheric environment [1-8].

The Pearl River Delta (PRD) region has experienced a remarkable economic development and rapid urbanization since the 1980s [9], and substantial green fields have been replaced by urban construction sites. The changes of landuse type over the PRD region due to urbanization and their impacts on the atmospheric environment have attracted increasing attention. A part of previous studies concerned the contributions of land-use change to regional climate, such as urban heat islands, urban dry islands, and precipitation. Lin et al. [10] simulated the impacts of land-use changes on climatic elements in dry autumn in the PRD region. The results showed that urban expansion caused distinct difference in simulated shelter-level temperature, humidity, surface fluxes, and the height of the planetary boundary layer. Cheng and Chan [11] simulated the effects of urbanization on seasonal precipitation in the PRD region since the 1980s and found that the increase in summer rainfall was mainly attributable to the strong urban heat island (UHI) effect, which enhances convective circulation over urban areas. Alternatively, the reduction in winter precipitation is due to drier northerly winds and increased atmospheric stability. Another part of studies concerned the contributions of land-use change to air quality, especially for ozone concentration. Li et al. [12] reported that the UHI effect in the PRD enhanced turbulent mixing and modified local circulations, initiating the UHI circulation and strengthening the sea breeze, which in turn 
caused a detectable decrease in daytime $\mathrm{O}_{3}$ concentrations and an increase in $\mathrm{O}_{3}$ around nocturnal rush hours. Wang et al. [13] presented two scenarios with urban maps from the Weather Research and Forecasting-Chemistry (WRFChem) model to represent urban distribution in the PRD in the early 1990s and 2000s. Month-long simulation results showed that urbanization in the PRD led to a decrease in the volume fraction of $\mathrm{NO}_{x}$ and VOC and an increase in $\mathrm{O}_{3}$ and $\mathrm{NO}_{3}$. Secondary organic aerosol increased in Foshan, Zhongshan, and west Guangzhou but decreased in Shenzhen and Dongguan. The above studies illustrate that land-use change due to urbanization can have significant impacts on meteorological conditions and air quality in the PRD region. These studies mainly focus on short-term simulations, while the different influences of land-use change during winter and summer have not been quantified. Besides, the previous studies mainly used the WRF default land-use datasets, United States Geological Survey (USGS) and Moderate Resolution Imaging Spectroradiometer (MODIS), to represent the distribution of urban land-use types in 1990s and 2000s [12-15], but the land-use types in PRD region are changing with the rapid urbanization. In this paper, the refined surface properties of the Global Land Cover 2009 (GLC2009) dataset were used to present the land cover conditions in the 2010s, which is more consistent with the current underlying surface situation in the PRD region [16], and Global Land Cover 2000 (GLC2000) dataset was chosen to present the land cover conditions in the 2000s. Two-month simulations in 2014 (January and July) in conjunction with two different landuse scenarios were conducted by the WRF-Chem model, to systematically investigate the impacts of land-use changes on the seasonal variability of atmospheric environment in PRD region. This paper includes four sections, the remaining are (2) Data and Methods, (3) Results and Discussion, and (4) Conclusion.

\section{Data and Methods}

2.1. WRF-Chem Configuration. WRF-Chem is a regional atmospheric dynamical-chemical model jointly developed by the US National Center for Atmospheric Research, the US Pacific Northwest National Laboratory, and the US National Oceanic and Atmospheric Administration [17]. This model includes dry deposition mechanism, gas-phase chemical mechanism, photolysis scheme, aerosol mechanism, and other chemical processes. This numerical model system is fully coupled "online" in the sense that its chemical and meteorological submodels use the same horizontal and vertical coordinates and the same physical parameterization, and feedbacks between chemical and meteorological processes can be included. Thus, the model can truly and synchronously describe atmospheric physical and chemical processes. The WRF-Chem model has been widely used in numerical simulation of regional air quality [18-20].

WRF-Chem version 3.5 was employed in this study. The defined domain is shown in Figure 1, centered at $23^{\circ} \mathrm{N}$ and $113^{\circ} \mathrm{E}$, and contains the whole $\mathrm{PRD}$ region with a grid resolution of $3 \mathrm{~km}$. The horizontal grid numbers were

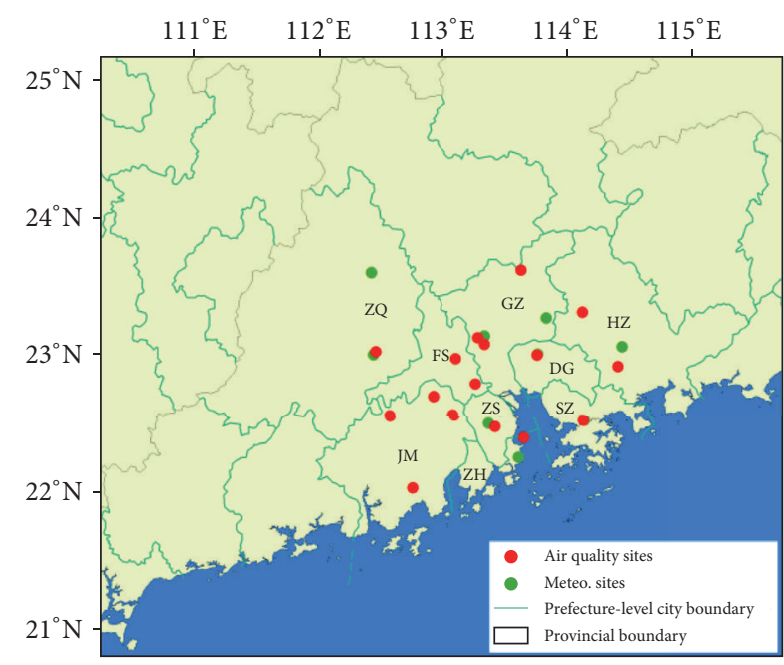

FIGURE 1: WRF-Chem domain setting and locations of the observation sites. GZ: Guangzhou, FS: Foshan, SZ: Shenzhen, DG: Dongguan, ZS: Zhongshan, ZQ: Zhaoqing, HZ: Huizhou, ZH: Zhuhai, and JM: Jiangmen.

$181 \times 160$ and 24 sigma levels up to $50 \mathrm{hPa}$ in the vertical direction. The physical parameterized options contain the Purdue Lin microphysics scheme [21], the Rapid Radiative Transfer Model (RRTM) longwave radiation [22], the Goddard shortwave scheme [23], the Yonsei University (YSU) boundary layer scheme [24], and the Noah Land Surface Model [25]. Since the simulation resolution in this study has reached a scale sufficient to distinguish clouds, the cumulus convection parameterization process was not used. The gasphase chemistry module CBM-Z [26] and the aerosol module MOSAIC using 4 sectional aerosol bins [27] were adopted. The initial and boundary conditions are interpolated from 1-degree resolution global reanalysis data from the National Center for Environmental Prediction (NCEP). The anthropogenic emissions were based on the emission inventory for the PRD region in 2012 provided by Professor Zheng of the South China University of Technology [28]. Biogenic emissions were calculated online by the Model of Emissions of Gases and Aerosols from Nature (MEGAN) [29].

2.2. Land-Use Datasets. In order to better understand the impacts of land-use change on the regional atmospheric environment in the $\mathrm{PRD}$, two land-use datasets for the PRD region are adopted in this study. GLC2000 is the land cover map derived from an automatic and regionally tuned classification of daily data acquired by the VEGETATION sensor on-board SPOT 4 in 2000 with a spatial resolution of $1 \mathrm{~km} \mathrm{[30],} \mathrm{which} \mathrm{represents} \mathrm{the} \mathrm{land} \mathrm{cover} \mathrm{conditions} \mathrm{in} \mathrm{the}$ 2000s (referred to as GLC2000 case hereafter). GLC2009 is the land cover map derived from data acquired by MEdium Resolution Imaging Spectrometer Full Resolution (MERIS FR) sensor on board the ENVISAT satellite for the year 2009 with a spatial resolution of $300 \mathrm{~m}$ [31], which represents the land cover conditions in the 2010s (referred to as GLC2009 case hereafter). Both datasets are created by European Space 

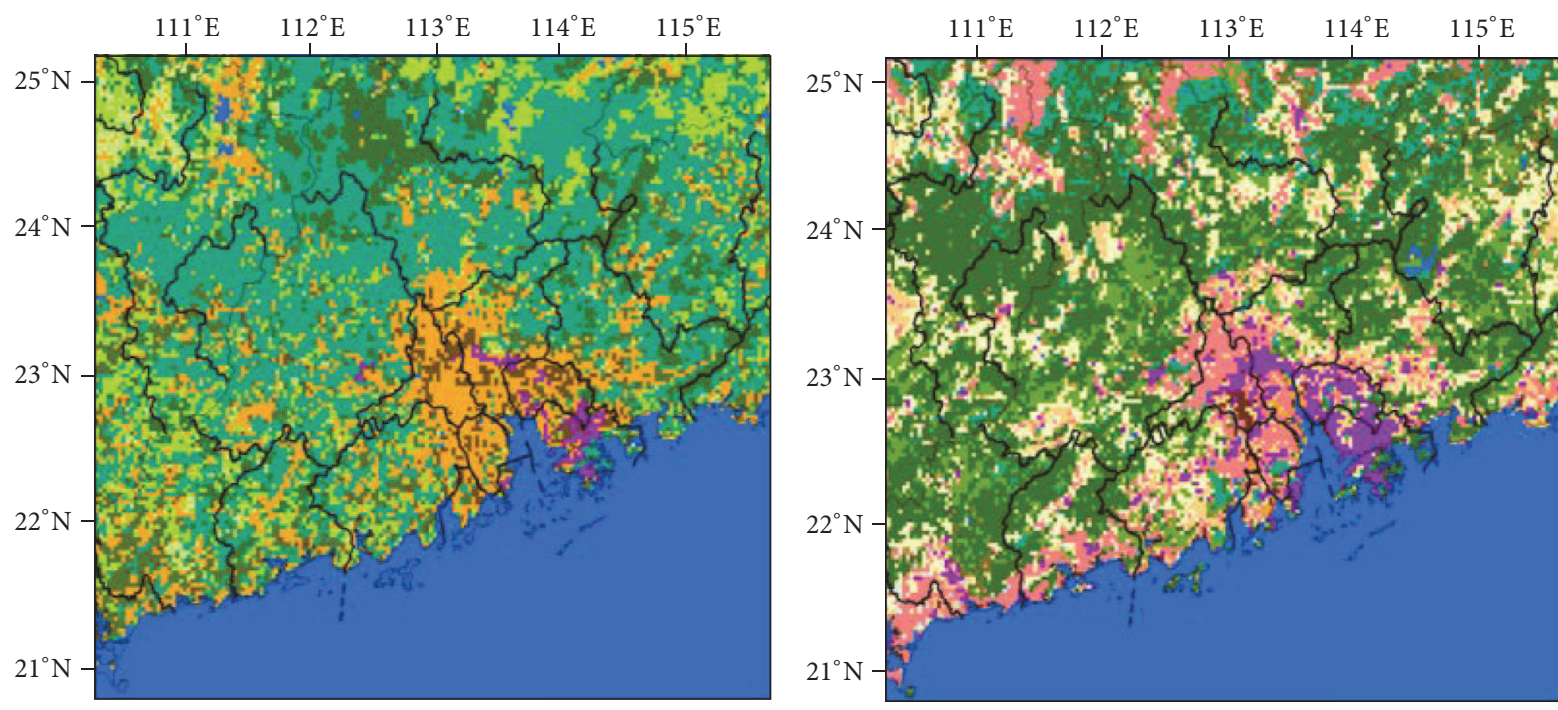

\begin{tabular}{l}
\hline Snow or Ice \\
\hline Bare ground tundra \\
\hline Herbaceous tundra \\
\hline Barren or sparsely vegetated \\
Wooden wetland \\
Herbaceous wetland \\
\hline Water bodies \\
Mixed forest \\
\hline Evergreen needleleaf forest \\
Evergreen broadleaf forest \\
\hline Deciduous needleleaf forest \\
\hline Deciduous broadleaf forest \\
Savanna \\
Mixed shrubland/grassland \\
Shrubland \\
\hline Grassland \\
Cropland/woodland mosaic \\
\hline Cropland/grassland mosaic \\
\hline Mixed dryland/irrigated cropland \\
Irrigated cropland and pasture \\
Dryland cropland and pasture \\
Urban and built-up land \\
Wooded tundra
\end{tabular}

(a)

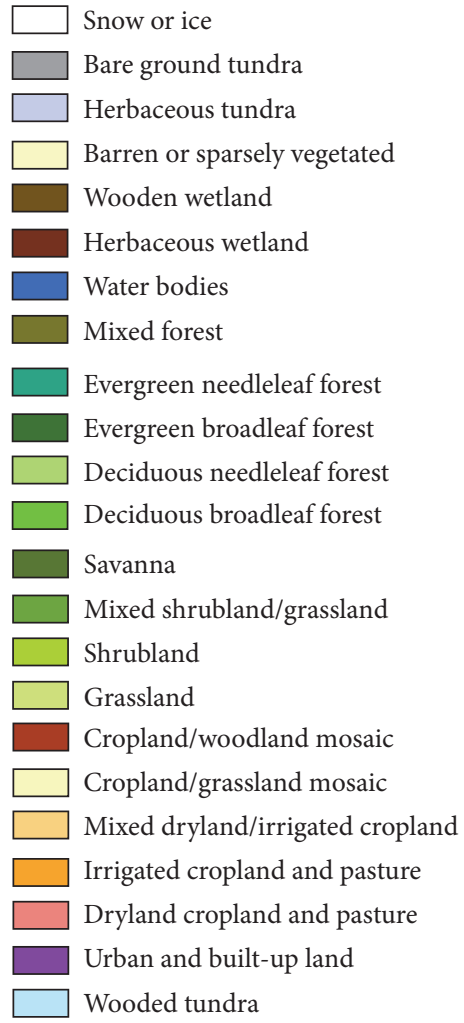

(b)

FIgURE 2: The landscape distributions of different land cover datasets in the PRD region: (a) the GLC2000 dataset; (b) the GLC2009 dataset.

Agency (ESA), are processed by the same GlobCover system, and followed the same classification module. Both of them contain 22 land cover classes following the Land Cover Classification System (LCCS), which describes land cover according to a series of preidentified classifiers and attributes organized in a hierarchical manner [32], and the GLC2009 and GLC2000 datasets have been mapped into the USGS classification, which can be directly invoked by WRF-Chem.
Figure 2 shows the distribution of major land cover types in the PRD region for GLC2000 and GLC2009. It is clear that the PRD region has undergone a significant land-use change from the 2000s to the 2010s. A detailed comparison emphasizes the differences between GLC2009 and GLC2000; the main conversion of land-use types was from irrigated cropland to urban land, especially in the central region along the Pearl River Estuary. The urban area expanded by as much 
TABLE 1: Comparison of simulated value and observed value of $2 \mathrm{~m}$ relative humidity, $2 \mathrm{~m}$ temperature, and $10 \mathrm{~m}$ wind speed.

\begin{tabular}{|c|c|c|c|c|c|c|c|c|}
\hline & Meteorological elements & OBS & SIM & MB & MAE & RMSE & $r$ & IOA \\
\hline \multirow{3}{*}{ January } & $\mathrm{Rh} 2(\%)$ & 77.46 & 75.14 & -2.32 & 0.10 & 8.69 & 0.90 & 0.99 \\
\hline & $\mathrm{T} 2\left({ }^{\circ} \mathrm{C}\right)$ & 14.81 & 16.83 & 2.02 & 0.17 & 2.80 & 0.92 & 0.99 \\
\hline & $\mathrm{WS} 10(\mathrm{~m} / \mathrm{s})$ & 1.82 & 3.74 & 1.92 & 1.33 & 2.22 & 0.78 & 0.89 \\
\hline \multirow{3}{*}{ July } & Rh2 (\%) & 77.91 & 74.96 & -2.95 & 6.64 & 7.87 & 0.76 & 0.93 \\
\hline & $\mathrm{T} 2\left({ }^{\circ} \mathrm{C}\right)$ & 29.46 & 29.82 & 0.36 & 1.14 & 1.40 & 0.75 & 0.99 \\
\hline & $\mathrm{WS} 10(\mathrm{~m} / \mathrm{s})$ & 1.94 & 3.00 & 1.06 & 1.12 & 1.46 & 0.83 & 0.91 \\
\hline
\end{tabular}

Note. The statistical measures here indicate the average of nine sites.

as $257 \%$, at the expense of irrigated cropland (a $96 \%$ reduction), and there are $4356 \mathrm{~km}^{2}$ in the simulation areas that are changed from other land-use types to urban land. Another noticeable difference between the two land datasets is the large growth of dryland cropland in FS and GZ, along with the removal of irritated cropland. It is noted that there are large areas of evergreen needleleaf forest in GLC2000 replaced by evergreen broadleaf forest in GLC2009 in the neighboring regions of $\mathrm{PRD}$. The main reason for the obvious change is the dataset's limited classification accuracy, caused by the coarse spatial resolutions. The spatial resolution of GLC2000 $\mathrm{t}$ and GLC2009 is $1 \mathrm{~km}$ and $300 \mathrm{~m}$, respectively. According to the field survey results, the distribution of vegetation in the PRD region presents a mixed state, such as needleleaf forest mixed with broadleaf forest and cropland mixed with grassland. Mixed forestland combines the characteristics of needleleaf and broadleaf forestland, and its multitemporal Normalized Difference Vegetation Index (NDVI) distribution characteristics are intermediate to those of needleleaf and broadleaf forestland. The complex of landscapes is beyond the spatial resolution capability of remote sensors. As a result, it is hard to use the coarse-resolution satellite data to distinguish the needleleaf and broadleaf forest accurately. Previous validation experiences show that the accuracies of cropland, water, and urban land are high in GLC2000 and GLC2009, while the mixed forestland and shrubland are more likely to be misclassified [33-35]. Thus, we mainly focus on the change of urban land in this study. Chen [36] pointed out that physical parameters are directly affected by different land-use types in Noah LSM surface scheme. According to the VEGPARM.TBL files in the WRF-Chem run directory, the physical parameter differences between varying types of vegetation are tiny when compared with the differences between irrigated cropland and urban land. As a result, the impact of vegetated areas change is negligible compared with the urban areas change, and the main influences on meteorological elements and air pollutants from land-use change were contributed by urban expansion.

Two simulation tests were set for January and July 2014, respectively, in this study. The simulation time for January was from 0000 UTC 30 December 2013 to 0000 UTC 01 February 2014, and the simulation time for July was from 0000 UTC 29 June to 0000 UTC 01 August 2014, with the first two days considered spin-up. The GLC2000 case and GLC2009 case of January and July 2014 adopted the same physical and chemical schemes and emissions inventory; the only difference is the land-use datasets.

\subsection{Observation Description and Model Evaluation}

2.3.1. Weather Conditions of January and July in 2014. In January 2014, the average temperature in Guangdong Province was $14^{\circ} \mathrm{C}, 0.6^{\circ} \mathrm{C}$ higher than that in the same period of normal years. The average precipitation was only $1 \mathrm{~mm}$, a drop of $98 \%$ compared with that in normal years. This month was affected by cold air twice, from January 4 to January 6 and from January 12 to January 22. During the intermission between cold air periods, the temperature rose due to southerly air currents. Guangdong was in the (quasi)uniform pressure field with calm or weak winds, high atmospheric stability, and low boundary layer. This was not conducive to pollutant dispersion, and apparent haze existed in most areas. In July, the average temperature in Guangdong Province was $29.3^{\circ} \mathrm{C}$, $0.8^{\circ} \mathrm{C}$ higher than that in the same period of normal years. The average precipitation in July was $164.9 \mathrm{~mm}$, a drop of $31.6 \%$ compared with the same period of normal years. The uneven distribution of precipitation in the northern areas is much less than the coastal areas. Affected by peripheral descending air flows due to Typhoons Rammasun, Matmo, and Halong, three intensive heat periods covering extensive areas occurred. Due to the effects of typhoon Rammasun, from July 18 to the morning of July 19, heavy to torrential rainstorms appeared in western Guangdong and heavy rains, heavy rainstorms, and isolated torrential rainstorms appeared in eastern Guangdong and the PRD region.

2.3.2. Model Evaluation. Simulation results of the GLC2009 case were verified using ground-level meteorological data and pollutant concentration monitoring data in the simulation area. Meteorological observation data were taken from daily observations from nine conventional ground meteorological observation sites in the PRD region. Pollutant concentration monitoring data were obtained from sixteen air quality monitoring sites in the $\mathrm{PRD}$ region, including hourly concentration data of $\mathrm{SO}_{2}, \mathrm{NO}_{2}, \mathrm{O}_{3}, \mathrm{PM}_{2.5}$, and $\mathrm{PM}_{10}$. The locations of the meteorological observation sites and air quality monitoring sites are marked in Figure 1.

Table 1 shows the verification results of $2 \mathrm{~m}$ temperature (T2), $2 \mathrm{~m}$ relative humidity (Rh2), and $10 \mathrm{~m}$ wind speed (WS10), wherein OBS denotes the average value of observations, SIM denotes the average value of simulations, MB denotes mean deviation, MAE denotes mean absolute error, RMSE denotes root mean square error, $r$ denotes the correlation coefficient, and IOA denotes the index of agreement. Clearly, temperature and wind speed are overestimated; 
TABLE 2: Comparison of simulated and observed concentrations of $\mathrm{SO}_{2}, \mathrm{NO}_{2}, \mathrm{O}_{3}, \mathrm{PM}_{2.5}$, and $\mathrm{PM}_{10}$.

\begin{tabular}{ccccccccc}
\hline & Pollutants & OBS & SIM & MB & MAE & RMSE & $r$ & IOA \\
\hline \multirow{4}{*}{ January } & $\mathrm{NO}_{2}\left(\mu \mathrm{g} / \mathrm{m}^{3}\right)$ & 53.04 & 47.46 & -5.58 & 21.3 & 25.53 & 0.73 & 0.93 \\
& $\mathrm{O}_{3}\left(\mu \mathrm{g} / \mathrm{m}^{3}\right)$ & 127.52 & 110 & -17.52 & 33.66 & 41.98 & 0.76 & 0.93 \\
& $\mathrm{SO}_{2}\left(\mu \mathrm{g} / \mathrm{m}^{3}\right)$ & 23.3 & 15.56 & -7.74 & 12.24 & 15.57 & 0.66 & 0.85 \\
& $\mathrm{PM}_{10}\left(\mu \mathrm{g} / \mathrm{m}^{3}\right)$ & 102.56 & 61.49 & -41.07 & 43.03 & 50.91 & 0.78 & 0.88 \\
& $\mathrm{PM}_{2.5}\left(\mu \mathrm{g} / \mathrm{m}^{3}\right)$ & 74.41 & 57.33 & -17.08 & 23.3 & 28.97 & 0.80 & 0.94 \\
& $\mathrm{NO}_{2}\left(\mu \mathrm{g} / \mathrm{m}^{3}\right)$ & 33.78 & 29.61 & -4.17 & 15.03 & 17.61 & 0.71 & 0.91 \\
\multirow{4}{*}{ July } & $\mathrm{O}_{3}\left(\mu \mathrm{g} / \mathrm{m}^{3}\right)$ & 135.43 & 94.46 & -40.97 & 63.31 & 79.69 & 0.66 & 0.91 \\
& $\mathrm{SO}_{2}\left(\mu \mathrm{g} / \mathrm{m}^{3}\right)$ & 15.7 & 9.88 & -5.82 & 9.9 & 12.32 & 0.61 & 0.82 \\
& $\mathrm{PM}_{10}\left(\mu \mathrm{g} / \mathrm{m}^{3}\right)$ & 46.51 & 20.55 & -25.96 & 26.3 & 32.27 & 0.73 & 0.87 \\
& $\mathrm{PM}_{2.5}\left(\mu \mathrm{g} / \mathrm{m}^{3}\right)$ & 28.05 & 17.46 & -10.59 & 12.51 & 17.57 & 0.77 & 0.91 \\
\hline
\end{tabular}

Note. The statistical measures here indicate the average of sixteen sites.

while relative humidity is underestimated by the WRF-Chem model in January and July. The correlation coefficients of Rh2 and T2 are over 0.9 and the IOA are over 0.99 in January, showing reasonably good model performances. Simulations in July do not perform as well as those in January, but the correlation coefficients are still over 0.75 and the IOA are over 0.9. Overall, simulation results can reasonably reflect actual atmospheric conditions.

Observed concentrations of $\mathrm{SO}_{2}, \mathrm{NO}_{2}, \mathrm{O}_{3}, \mathrm{PM}_{10}$, and $\mathrm{PM}_{2.5}$ were used to evaluate the GLC2009 case performance in this study. The evaluation results are shown in Table 2, and it is clear that the GLC2009 case captures pollutants variations well since the correlation coefficients are approximately 0.7 and the IOA are over 0.8 . However, the model underestimates these five pollutant concentrations in both January and July. These biases are partly attributable to the overestimation of $\mathrm{T} 2$, which induces an increase in the planetary boundary layer height (PBLH) and causes pollutant well mixing within the planetary boundary layer. Furthermore, limitations of the chemical schemes and uncertainties in the emissions inventory may also contribute to these biases.

In summary, the GLC2009 case reproduced meteorological and chemical conditions well with observations.

\section{Results and Discussion}

\subsection{Impacts on Meteorology}

3.1.1. Impacts on Temperature. The $2 \mathrm{~m}$ temperature is affected directly by land-use change. Figures $3(a)$ and $3(b)$ show the simulation results of T2 in the GLC2009 case for January and July, and it can be seen that in January the temperatures in GZ, FS, DG, ZS, and SZ were significantly higher than those in other cities. In July, the average temperature in the simulation region reached $30^{\circ} \mathrm{C}$, and the average temperature in the border area between GZ and FS and DG and SZ was as high as $32^{\circ} \mathrm{C}$. Figures $3(\mathrm{c})$ and $3(\mathrm{~d})$ illustrate the warming effect of urban expansion. Increase of $2 \mathrm{~m}$ temperature is more obvious in July than that in January, with magnitude of $0.24^{\circ} \mathrm{C}$ for January and $0.27^{\circ} \mathrm{C}$ for July. Meanwhile, the patterns in the $2 \mathrm{~m}$ temperature difference are similar to the spatial plots of urban land-use change, with the border area between
GZ and DG along the Pearl River Estuary and the coastal areas of SZ experiencing the largest increase in temperature. Codevelopment of GZ and FS also caused the temperature in their border region to increase significantly. The vertical distributions of monthly-average temperature differences over GZ for January and July are shown in Figures 3(e) and 3(f). Within the whole boundary layer, temperatures rose by differing magnitudes during the daytime and nighttime. Temperatures rose more markedly during the nighttime than during the daytime. The conversion of irrigated cropland to urban land directly changed the surface properties directly, such as surface albedo and heat capacity, and affected the surface radiation characteristics and then modified the surface temperature. Additionally, the $2 \mathrm{~m}$ temperature is affected directly by the sensible heat flux (SHF) that is impacted by land use [4], and the T2 increases are consistent with the differences of sensible heat flux between the GLC20009 case and the GLC2000 cases (not shown). It is noted that the increase of T2 is larger in July when compared with increase in January. This phenomenon may be attributable to the difference of irrigated cropland characteristics in different seasons [37]. Additionally, elevation angle of the sun is higher in July than in January, stronger solar radiation reaches the surface, and urban canopies capture more heat energy due to the building trapping effect in summer. The effects of landuse change on rising atmospheric temperature were more significant at night, partly because the heat capacity of urban land is greater than that of farmland, and, thus, a large amount of solar radiation is absorbed and trapped by buildings during the day and more heat flux is released overnight [38]. Furthermore, since the boundary layer height of the daytime was somewhat higher than that of the nighttime, the extra heat released by the urban land was allocated into a relatively short atmospheric column. As a result, the shelterlevel temperature of urban areas increased more during the nighttime.

3.1.2. Impacts on Moisture. In this study, $2 \mathrm{~m}$ water vapor content (Q2) and $2 \mathrm{~m}$ relative humidity are selected as indicators for the moisture field. In the updated land-use dataset, a large amount of rural land has been replaced with the built-up land characterized by inferior permeability and lower vegetation 


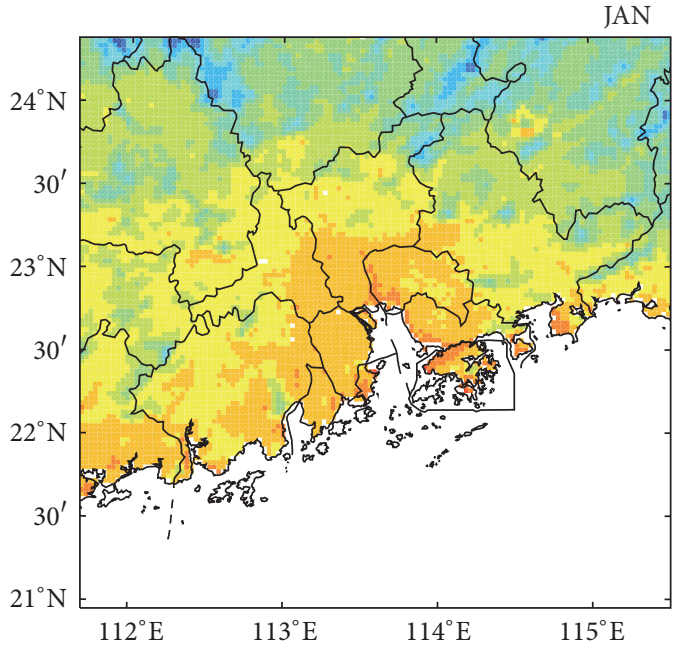

(a) $\mathrm{T} 2\left({ }^{\circ} \mathrm{C}\right)$

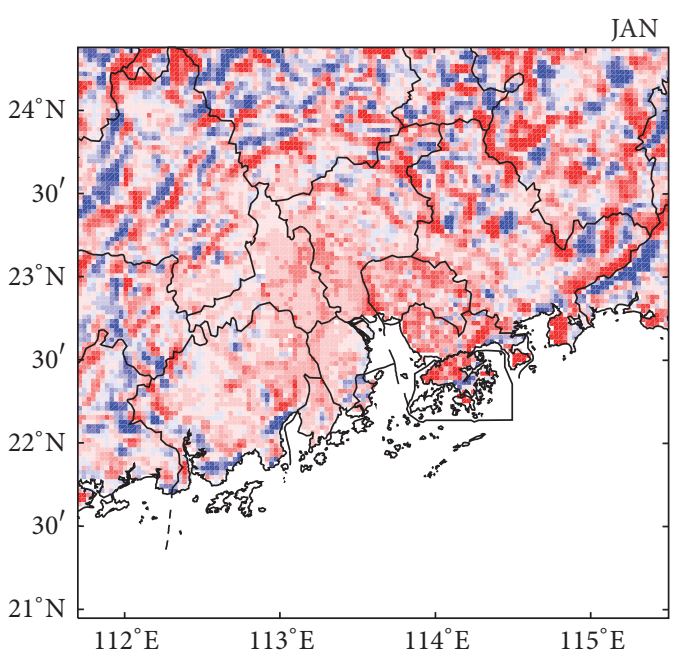

(c) Diff. of $\mathrm{T} 2\left({ }^{\circ} \mathrm{C}\right)$

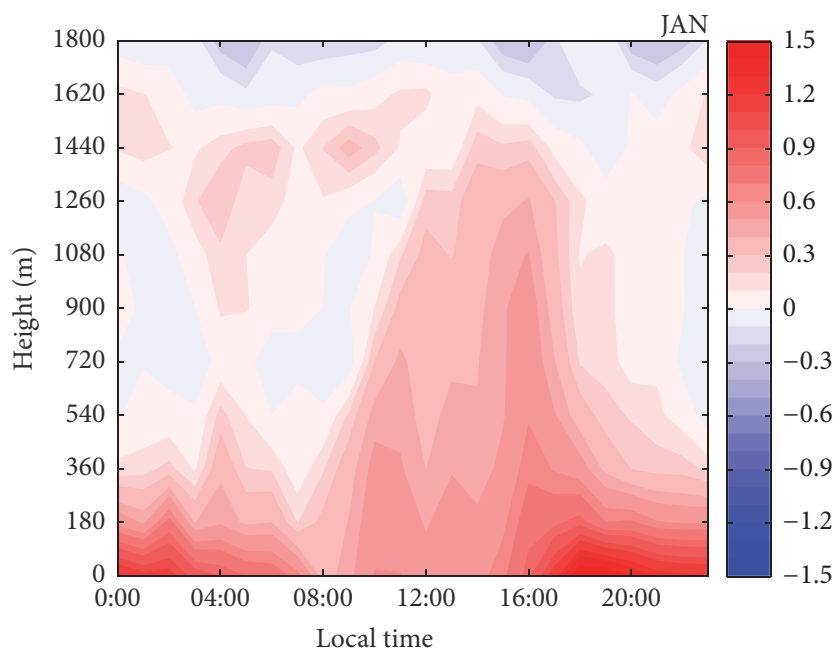

(e) Diff. of $\mathrm{T}\left({ }^{\circ} \mathrm{C}\right)$
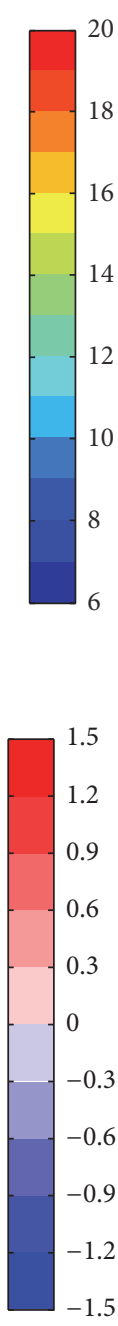

$-1.5$

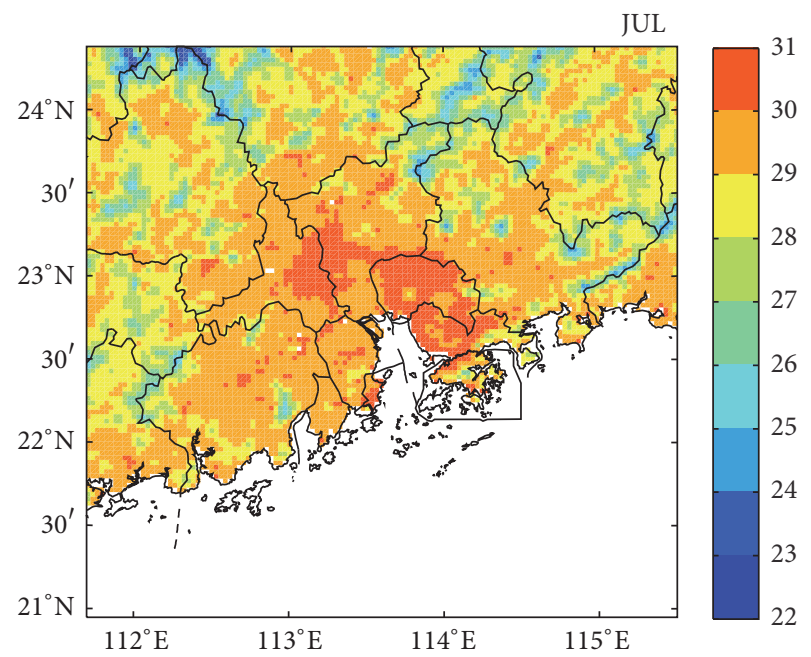

(b) $\mathrm{T} 2\left({ }^{\circ} \mathrm{C}\right)$

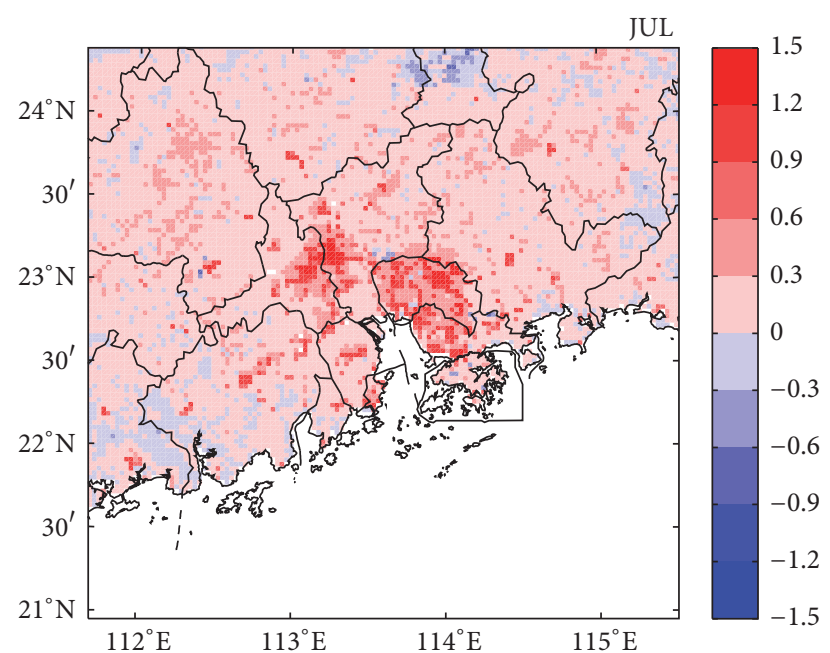

(d) Diff. of T2 $\left({ }^{\circ} \mathrm{C}\right)$

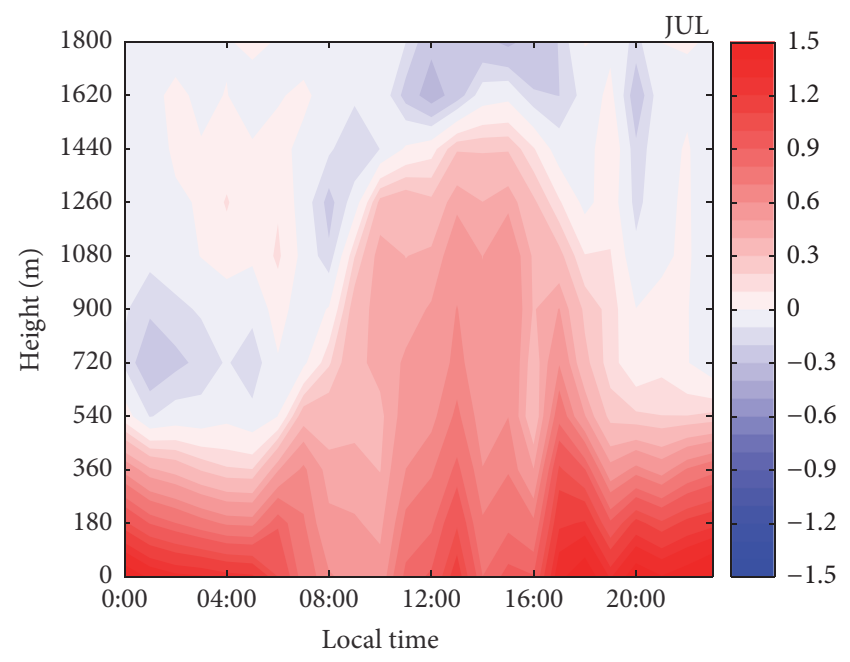

(f) Diff. of $\mathrm{T}\left({ }^{\circ} \mathrm{C}\right)$

FIGURE 3: The simulated spatial distribution of monthly-average $2 \mathrm{~m}$ temperature $\left({ }^{\circ} \mathrm{C}\right)$ in the GLC2009 case (a, b), spatial distribution (c, d), and vertical distribution over GZ $(e, f)$ of monthly-average temperature differences $\left({ }^{\circ} \mathrm{C}\right)$ (differences = GLC2009 - GLC2000). 


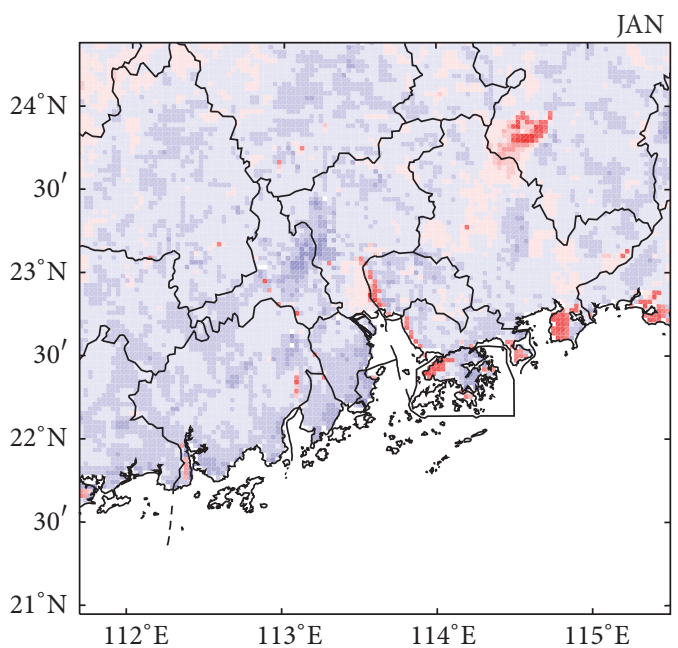

(a) Diff. of Q2 (g/kg)

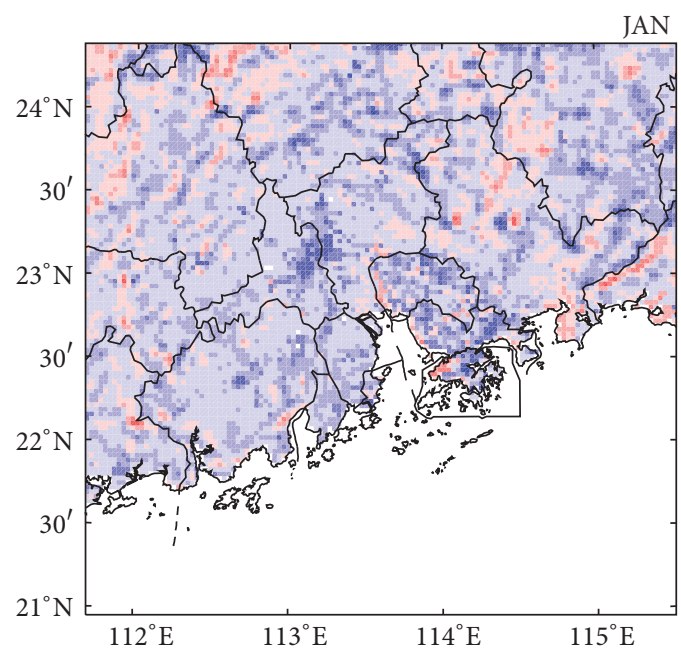

(c) Diff. of Rh2 (\%)

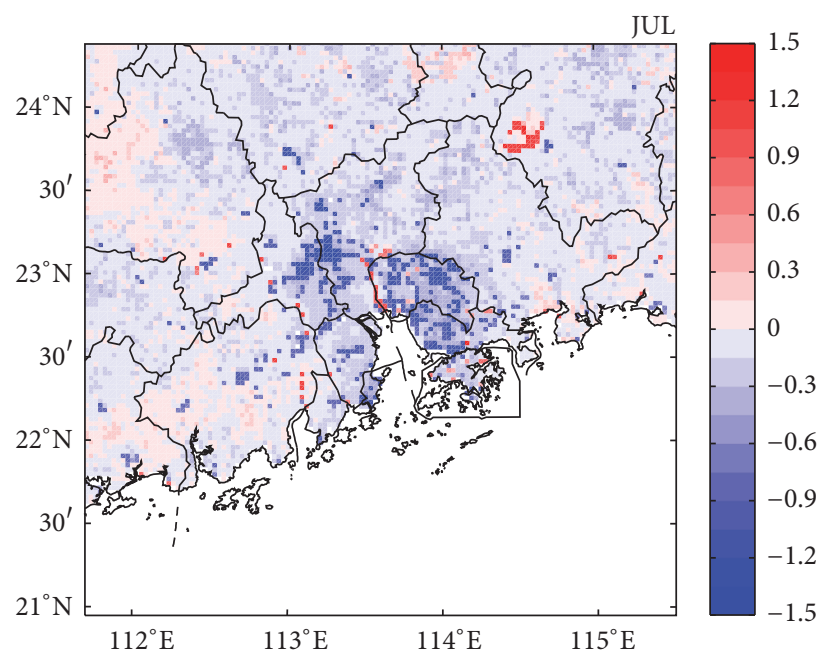

(b) Diff. of Q2 (g/kg)

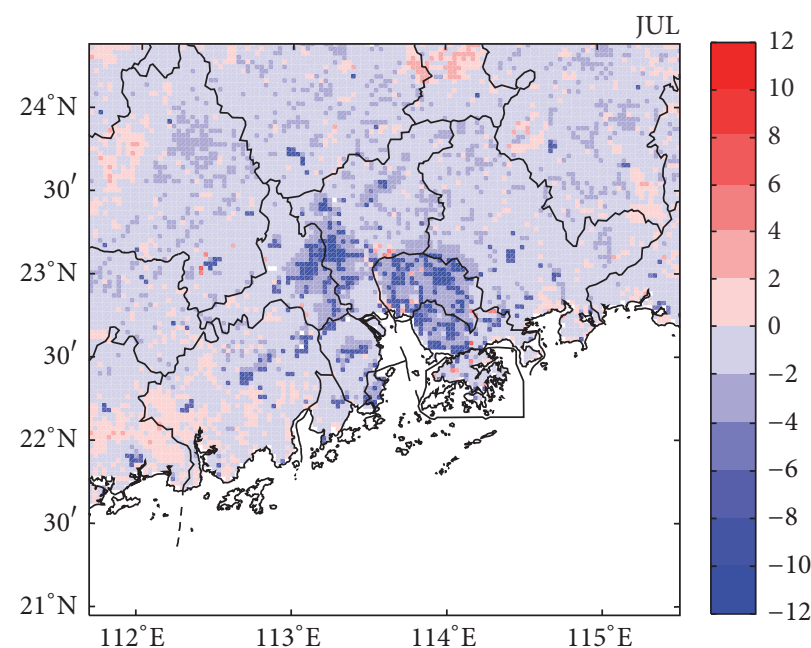

(d) Diff. of Rh2 (\%)

FIGURE 4: Spatial distribution of monthly-average Q2 differences (g/kg) (a, b) and Rh2 differences (\%) (c, d) between the GLC2009 case and the GLC2000 case (differences = GLC2009 - GLC2000).

coverage, so the latent heat flux and the volume of evapotranspiration decreased. Moreover, the upward transportation of vapor increased due to the enhanced turbulence caused by urban expansion, and this resulted in a decrease in the absolute vapor content at the lower layer within urban areas, as shown in Figures 4(a) and 4(b). The monthly averaged Q2 decreased $0.07 \mathrm{~g} / \mathrm{kg}$ in January and $0.28 \mathrm{~g} / \mathrm{kg}$ in July, with a maximum decrease of $1.33 \mathrm{~g} / \mathrm{kg}$ in January and $1.66 \mathrm{~g} / \mathrm{kg}$ in July. The relative humidity represents humidity of the air parcel and is subject to coinfluences from absolute humidity and temperature. Rising temperatures in urban areas cause the saturated vapor pressure to increase while the absolute vapor content decreases; therefore, the relative humidity decreased. The decreases in the monthly averaged $\mathrm{Rh} 2$ for January and July are $2.02 \%$ and $2.23 \%$, respectively, and the spatial distributions of the differences are shown in Figures 4(c) and 4(d). The differences of Q2 and Rh2 in July case are larger as compared with January; this seasonal evolution is partly attributed to larger increase of air temperature in July. The regions with noticeable decrease in relative humidity matched with the areas experiencing rising temperature, and they were most prevalent in GZ, FS, DG, and SZ.

3.1.3. Impacts on Wind. Changes in surface roughness, albedo, and other physical parameters due to land-use change also impact wind speed and direction. As shown in Figures 5 (a) and 5(b), the $10 \mathrm{~m}$ wind pattern is dominated by a strong northeasterly wind in January and a southerly wind in July. The friction and drag of buildings decrease the $10 \mathrm{~m}$ wind speed in January and July, the monthly averaged $10 \mathrm{~m}$ wind speed in the PRD region decreased by $0.19 \mathrm{~m} / \mathrm{s}$ in January and $0.16 \mathrm{~m} / \mathrm{s}$ in July, and the maximum decrease of $10 \mathrm{~m}$ wind speed may reach $2.5 \mathrm{~m} / \mathrm{s}$ in the Pearl River Estuary. Moreover, the $10 \mathrm{~m}$ wind direction changed at the same time. The monthly averaged differences of wind vector denote that 


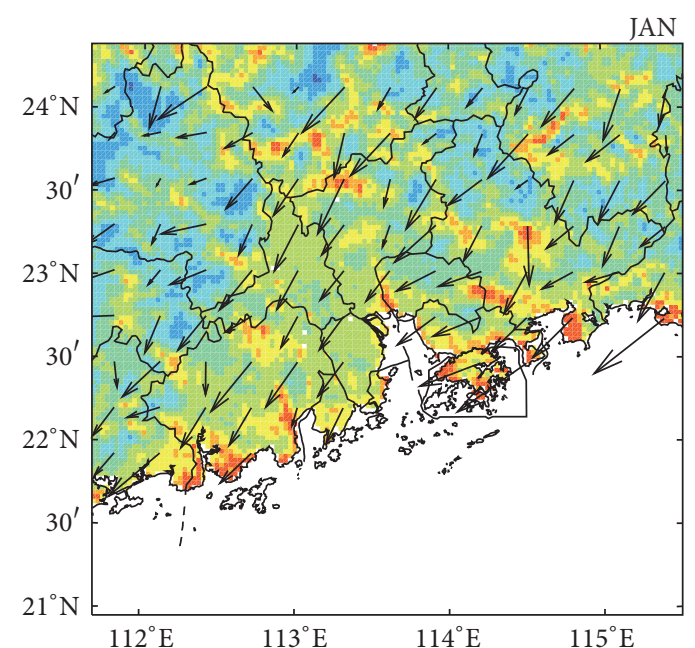

(a) $10 \mathrm{~m}$ wind

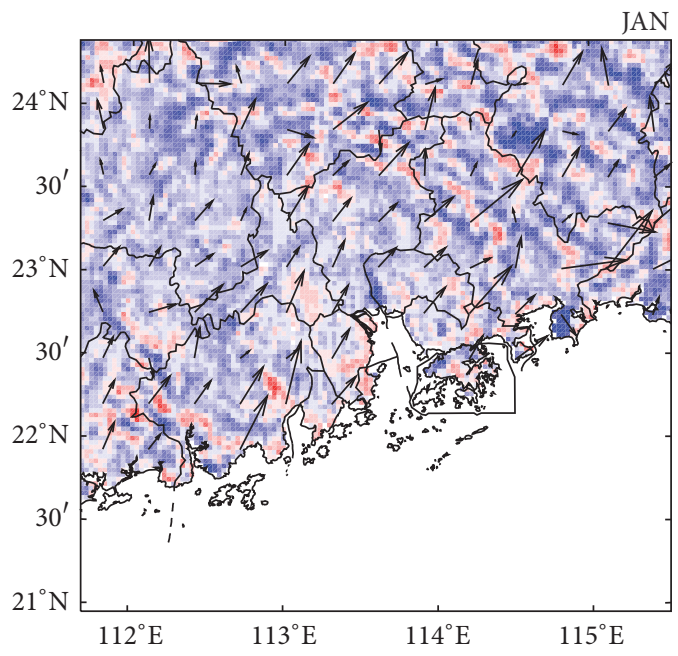

(c) Diff. of $10 \mathrm{~m}$ wind
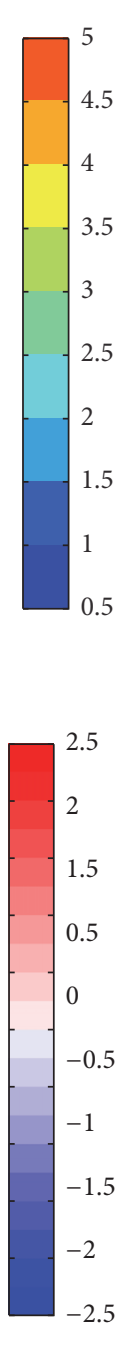

年

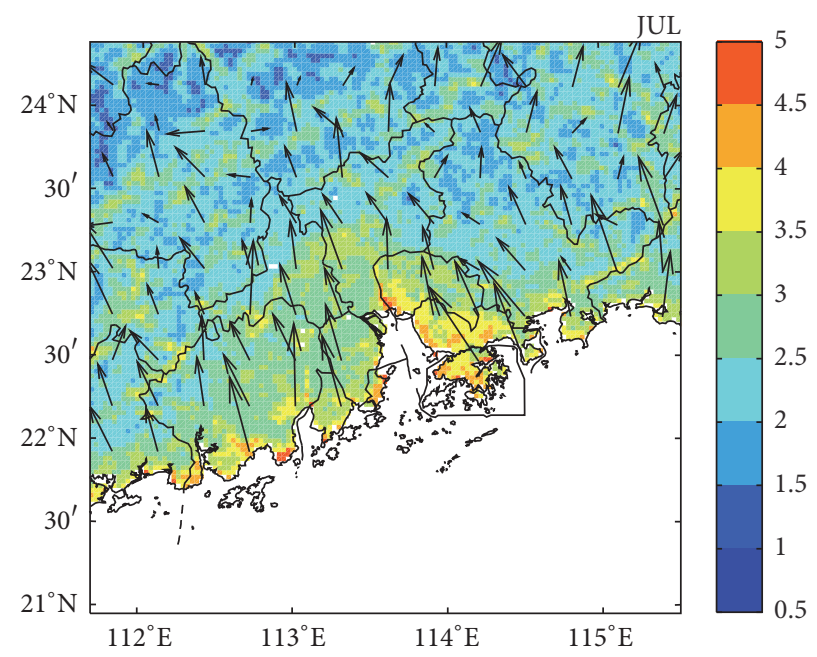

(b) $10 \mathrm{~m}$ wind

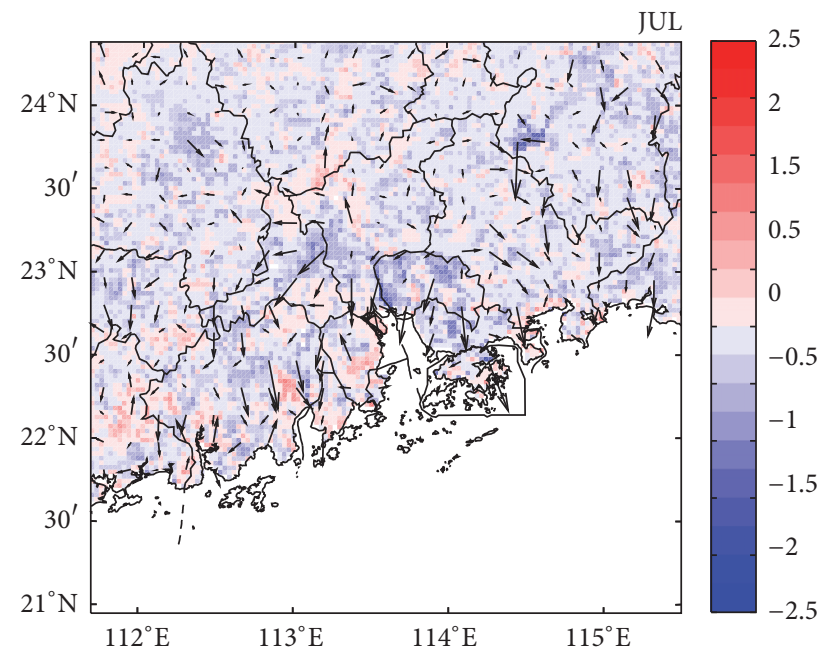

(d) Diff. of $10 \mathrm{~m}$ wind

FIGURE 5: The simulated spatial distribution of monthly-average $10 \mathrm{~m}$ wind in the GLC2009 case $(\mathrm{a}, \mathrm{b})$ and spatial distribution of monthlyaverage $10 \mathrm{~m}$ wind differences between the GLC2009 case and the GLC2000 case (c, d) (differences = GLC2009 - GLC2000).

the northerly wind in January and southerly wind in July are weakened by land-use change.

3.1.4. Impacts on Planetary Boundary Layer Height. The planetary boundary layer height is a crucial variable that affects pollutant transport and dispersion. After updating the land-use dataset, the spatial differences of monthly averaged PBLH at 02:00 Local Standard Time (LST) and 14:00 LST are shown in Figure 6. Urban expansion caused PBLH in the PRD region to increase during both the daytime and nighttime, and the monthly averaged PBLH in January and July increased by $9.96 \mathrm{~m}$ and $29.80 \mathrm{~m}$, respectively. This seasonal difference is attributable to different increases of $2 \mathrm{~m}$ temperature in January and July. The increase in temperature led to an increase in turbulence intensity and convective instability in the boundary layer, resulting in a higher PBLH. Meanwhile, the boundary layer was more stable at nighttime, so the impact on PBLH differences was much larger during the daytime, with the maximum value of PBLH increase occurring at 14:00 LST in January and July and reaching as high as $644.90 \mathrm{~m}$ and $688.81 \mathrm{~m}$, respectively. However, since PBLH during the daytime was much higher than that at nighttime, relative differences of PBLH at nighttime were greater than those during the daytime. The changes in the PBLH have corresponding effects on the dispersion and transport of air pollutants.

3.2. Impacts on the Regional Atmospheric Environment. The above analyses have demonstrated that changes in landuse lead to significant changes in meteorological conditions within the planetary boundary layer. Studies have shown that air pollution is closely associated with specific meteorological factors [39, 40], and with fixed pollution emissions inventory, pollutant concentrations depend primarily on meteorological 


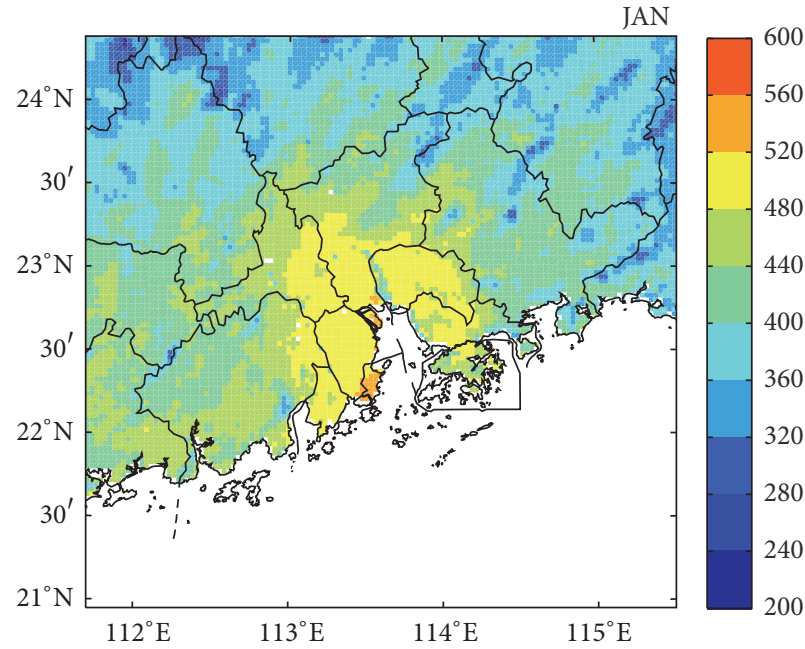

(a) PBLH (m)

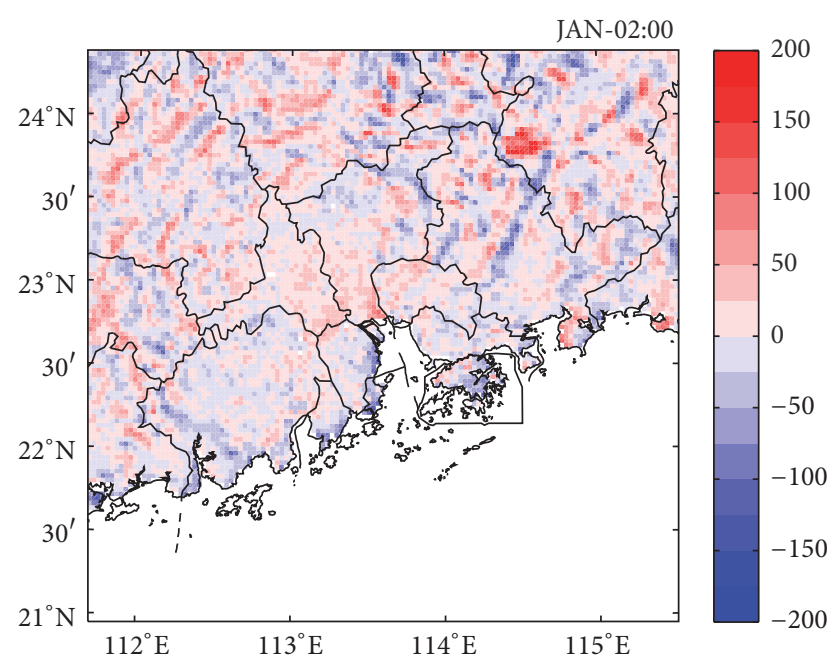

(c) Diff. of PBLH (m)

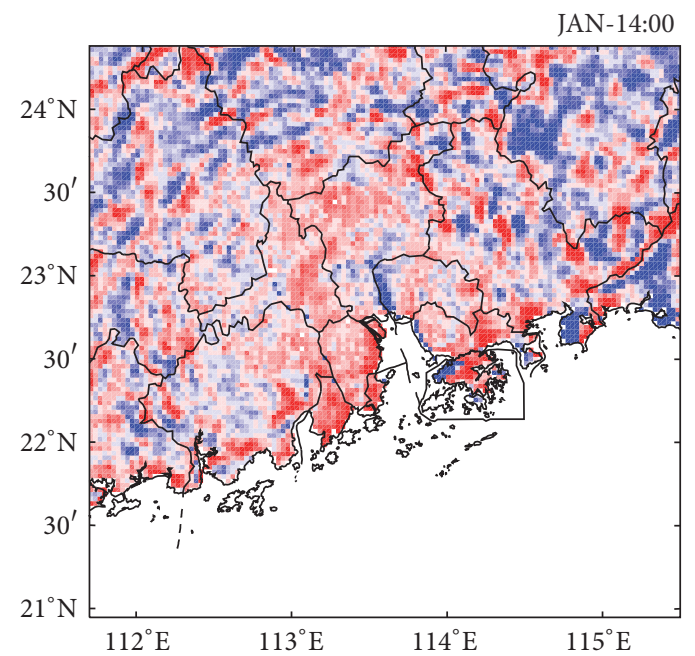

(e) Diff. of PBLH (m)

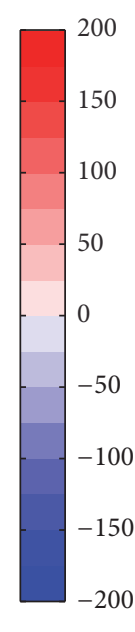

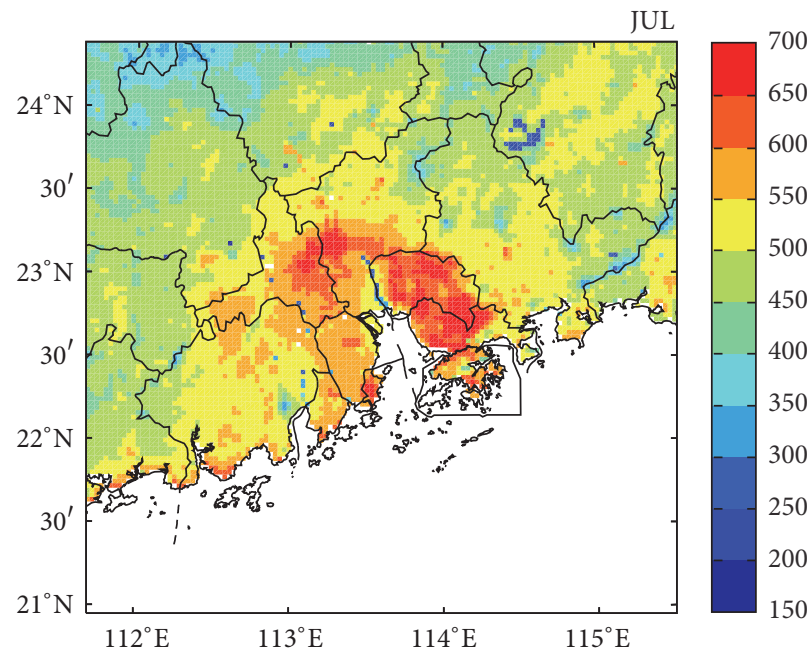

(b) PBLH (m)

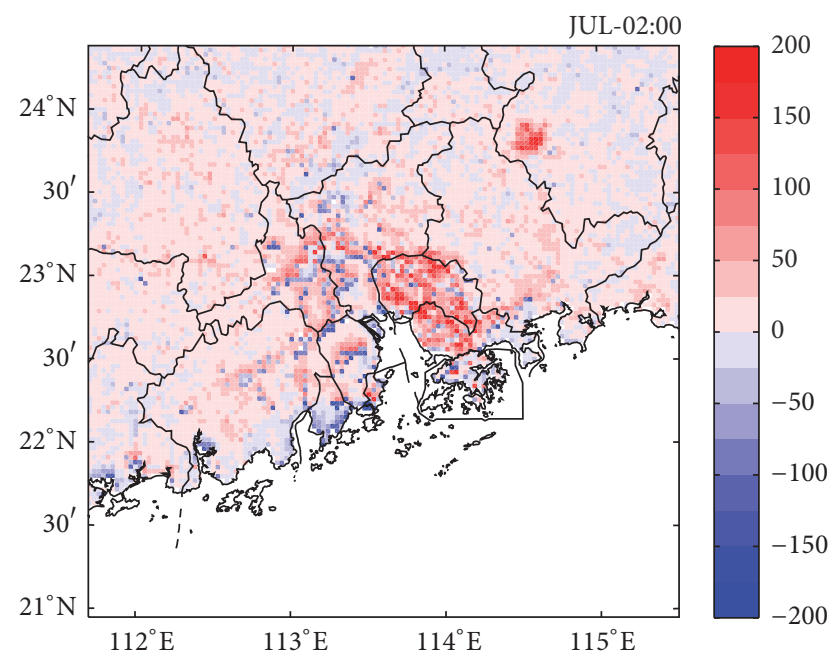

(d) Diff. of PBLH (m)

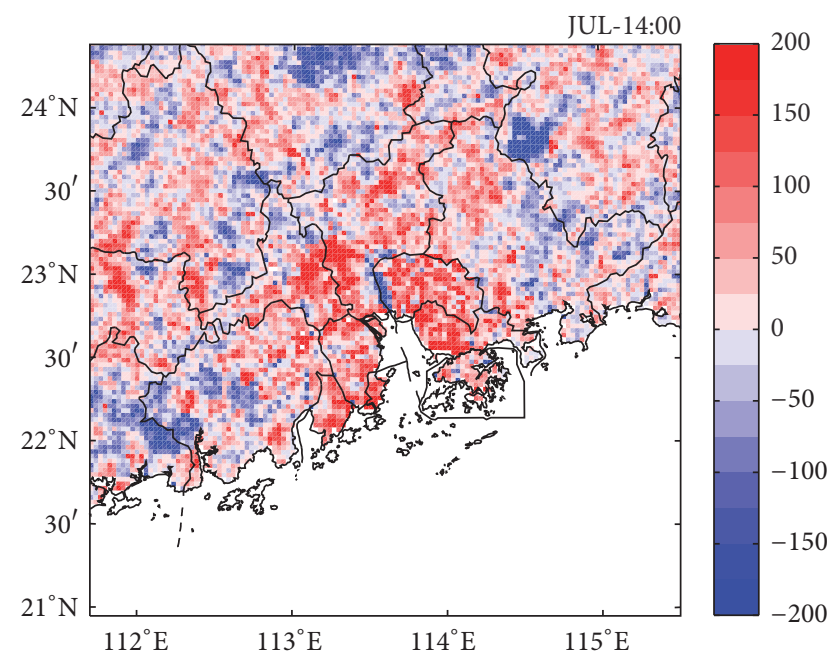

(f) Diff. of PBLH (m)

FIgURE 6: The simulated spatial distribution of monthly-average PBLH (m) in the GLC2009 case (a, b) and spatial distribution of PBLH differences (m) at 02:00 LST (c, d) and 14:00 LST (e, f) between the GLC2009 case and the GLC2000 case (differences = GLC2009 - GLC2000). 


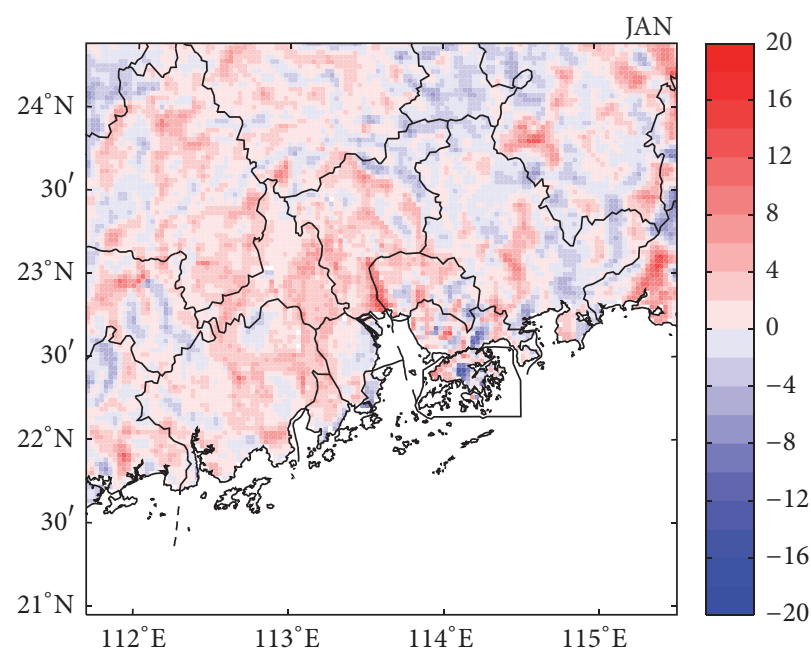

(a) Diff. of $\mathrm{O}_{3}\left(\mu \mathrm{g} / \mathrm{m}^{3}\right)$

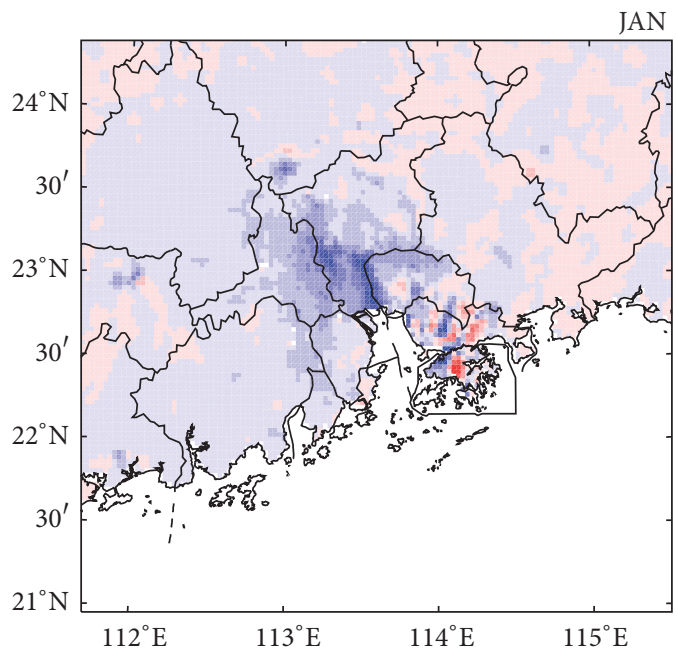

(c) Diff. of $\mathrm{NO}_{x}\left(\mu \mathrm{g} / \mathrm{m}^{3}\right)$

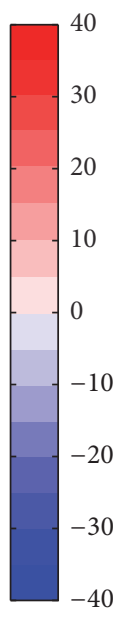

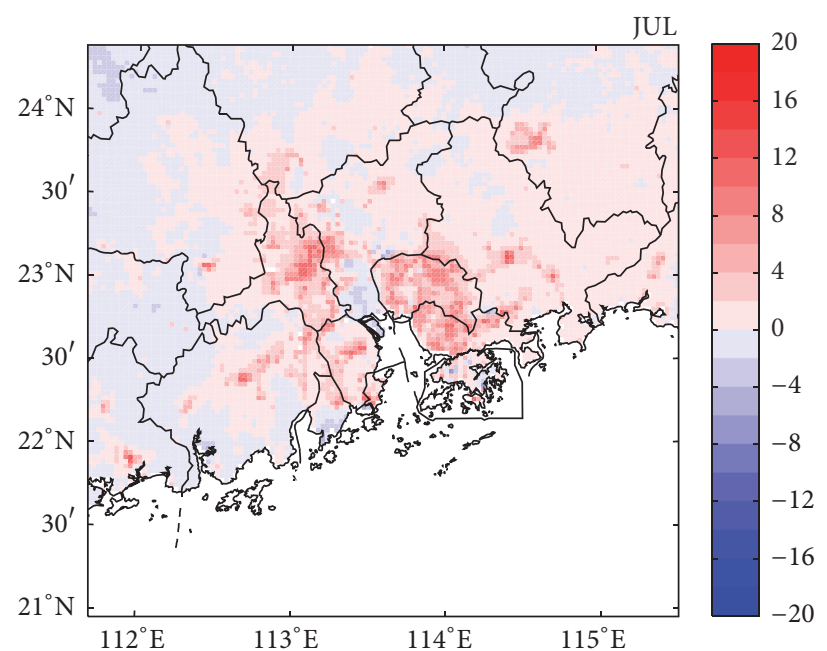

(b) Diff. of $\mathrm{O}_{3}\left(\mu \mathrm{g} / \mathrm{m}^{3}\right)$

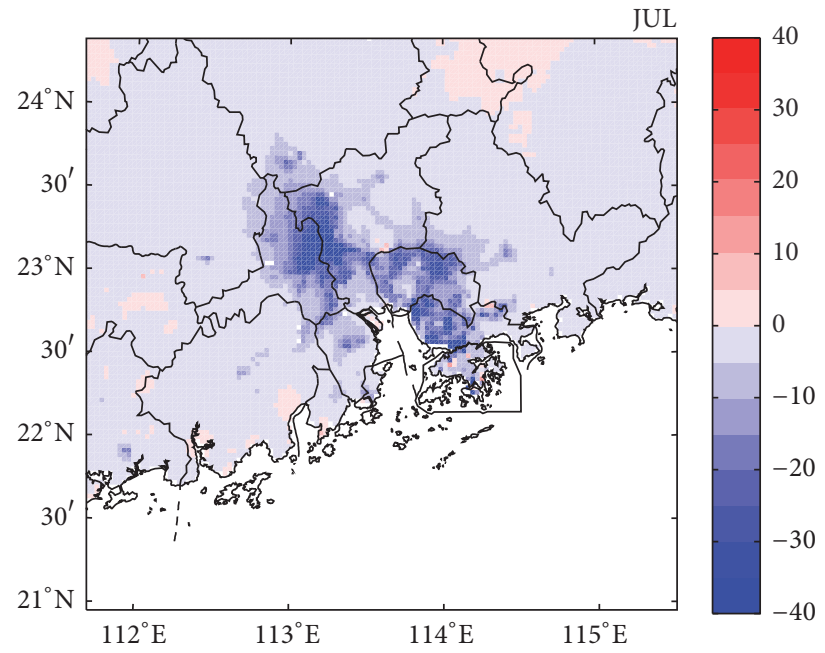

(d) Diff. of $\mathrm{NO}_{x}\left(\mu \mathrm{g} / \mathrm{m}^{3}\right)$

FIGURE 7: Spatial distribution of monthly-average $\mathrm{O}_{3}$ concentration differences $\left(\mu \mathrm{g} / \mathrm{m}^{3}\right)(\mathrm{a}, \mathrm{b})$ and $\mathrm{NO}_{x}$ concentration differences $\left(\mu \mathrm{g} / \mathrm{m}^{3}\right)$ (c, d) between the GLC2009 case and the GLC2000 case (differences = GLC2009 - GLC2000).

conditions. Thus, changes in meteorological factors will affect the distribution of atmospheric pollutants. In this study, two major atmospheric pollutants, $\mathrm{O}_{3}$ and $\mathrm{PM}_{2.5}$, were chosen for analysis, and the influence of land-use change on the regional atmospheric environment was investigated.

3.2.1. Impacts on Tropospheric Ozone. Tropospheric ozone is generated primarily by chemical reactions of primary pollutants such as nitrogen oxides $\left(\mathrm{NO}_{x}=\mathrm{NO}+\mathrm{NO}_{2}\right)$ and volatile organic compounds (VOCs). The spatial distribution of $\mathrm{O}_{3}$ concentration is the result of complex processes involving photochemical reactions, meteorology, and primary pollutant emissions [8]. In other words, any changes in these complex chemical reaction processes can affect $\mathrm{O}_{3}$.

Figures $7(\mathrm{a})$ and $7(\mathrm{~b})$ show the spatial distribution of monthly averaged $\mathrm{O}_{3}$ concentration differences caused by land-use change in January and July. It can be seen that $\mathrm{O}_{3}$ concentration increased substantially in most of the
PRD cities. The monthly averaged surface $\mathrm{O}_{3}$ concentration increased by $0.93 \mu \mathrm{g} / \mathrm{m}^{3}$ in January and $1.61 \mu \mathrm{g} / \mathrm{m}^{3}$ in July, and the spatial distributions of the $\mathrm{O}_{3}$ increases are similar to those of $2 \mathrm{~m}$ temperature increases, illustrating the strong correlation of $\mathrm{O}_{3}$ with temperature. Higher temperatures increase photochemical reaction rates to produce more $\mathrm{O}_{3}$ and increase both biogenic and evaporative emissions of anthropogenic VOCs $[41,42]$. Previous study indicated that the current ozone formation in the PRD region occurs under $\mathrm{NO}_{x}$-saturated condition [43], which means that VOCs are the most important compounds in the production of $\mathrm{O}_{3}$. Thus, higher VOC concentrations are conducive to the production of more $\mathrm{O}_{3}$ during daytime. Lower wind speeds decrease dry deposition velocities of $\mathrm{O}_{3}$ and simultaneously facilitate $\mathrm{O}_{3}$ accumulation, while increases in PBLH lead to $\mathrm{O}_{3}$ dilution within planetary boundary layer. The net influences of these factors led to the increase of surface $\mathrm{O}_{3}$ concentration. 


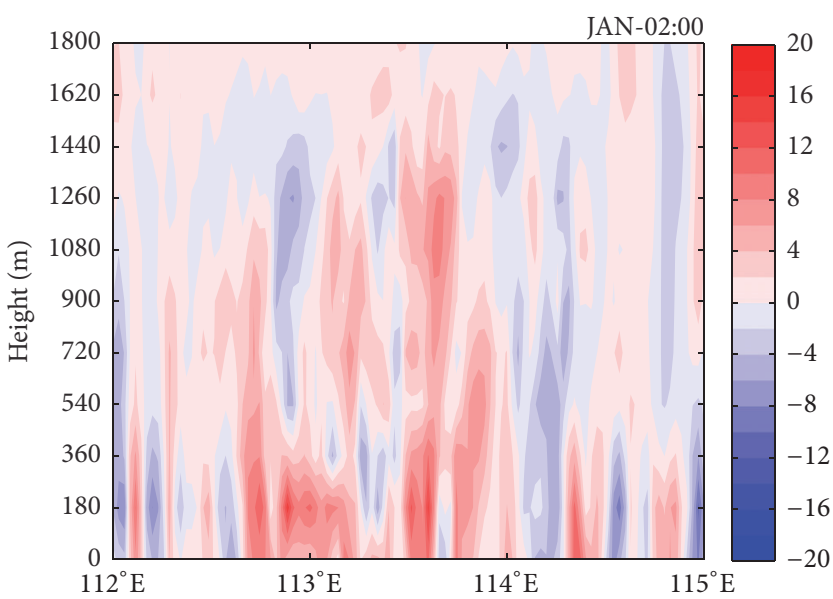

(a) Diff. of $\mathrm{O}_{3}\left(\mu \mathrm{g} / \mathrm{m}^{3}\right)$

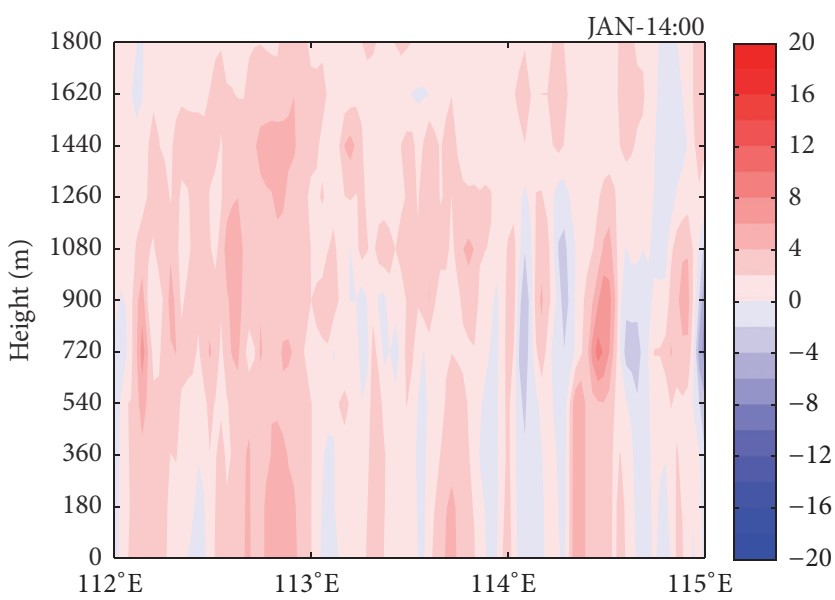

(c) Diff. of $\mathrm{O}_{3}\left(\mu \mathrm{g} / \mathrm{m}^{3}\right)$

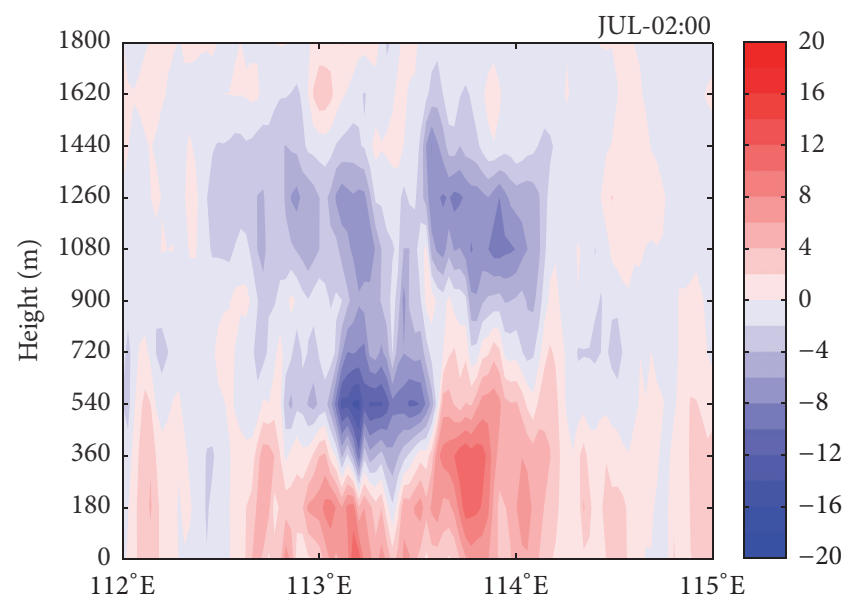

(b) Diff. of $\mathrm{O}_{3}\left(\mu \mathrm{g} / \mathrm{m}^{3}\right)$

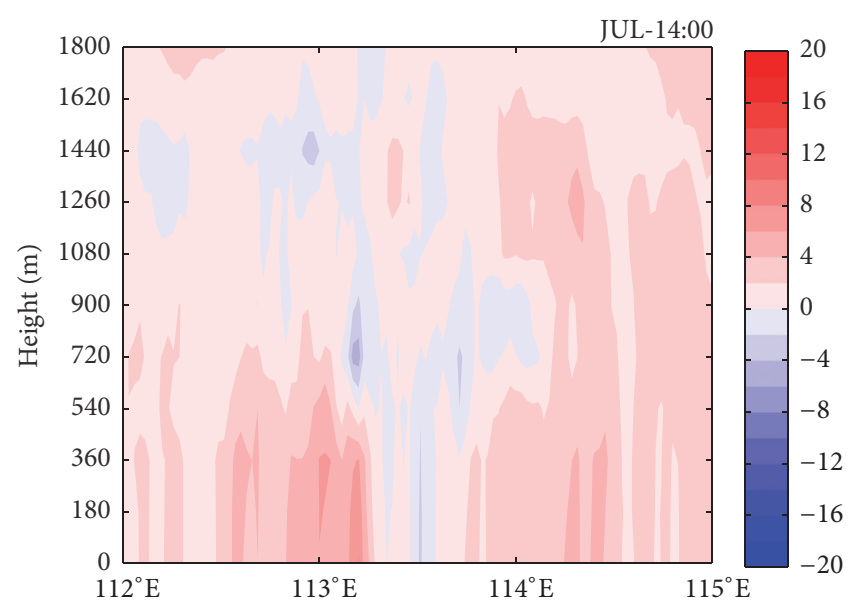

(d) Diff. of $\mathrm{O}_{3}\left(\mu \mathrm{g} / \mathrm{m}^{3}\right)$

FIGURE 8: Vertical cross sections of $\mathrm{O}_{3}$ concentration differences $\left(\mu \mathrm{g} / \mathrm{m}^{3}\right)$ along $23.5^{\circ} \mathrm{N}$ at 02:00 LST $(\mathrm{a}, \mathrm{b})$ and 14:00 LST (c, d) between the GLC2009 case and the GLC2000 case (differences = GLC2009 - GLC2000).

By comparing the vertical cross sections of $\mathrm{O}_{3}$ concentration differences along $23.5^{\circ} \mathrm{N}$ at 02:00 LST and 14:00 LST, as shown in Figure 8, we discovered that the increase in the monthly averaged surface $\mathrm{O}_{3}$ concentration during the nighttime was larger than that of the daytime. Generally, the $\mathrm{O}_{3}$ concentration increased significantly at the lower layer while decreasing at the higher layer at nighttime. $\mathrm{O}_{3}$ produced during the daytime that is trapped in the residual layer will mix down at nighttime. Stronger mixing down due to higher PBLH explains the larger increase in $\mathrm{O}_{3}$ concentration at nighttime. Land-use change also impacts the precursors of $\mathrm{O}_{3}$, such as $\mathrm{NO}_{x}$. Figures $7(\mathrm{c})$ and $7(\mathrm{~d})$ show the spatial distributions of monthly-average $\mathrm{NO}_{x}$ concentration differences, with obvious decreases in the Pearl River Estuary after land-use change for both January and July. The higher PBLH favors the vertical diffusion of air pollutants and results in relatively low ground-level $\mathrm{NO}_{x}$ concentrations, reducing the titration rate at ground level and subsequently resulting in increased ground-level $\mathrm{O}_{3}$ during the nighttime.
3.2.2. Impacts on $P M_{2.5}$. The impact of land-use change on the $\mathrm{PM}_{2.5}$ concentration is shown in Figure 9. It can be observed that change in land-use led to a reduction of areas with high $\mathrm{PM}_{2.5}$ concentration. In January and July, monthly-average surface $\mathrm{PM}_{2.5}$ concentration decreased by $1.58 \mu \mathrm{g} / \mathrm{m}^{3}$ and $3.76 \mu \mathrm{g} / \mathrm{m}^{3}$, respectively, and the negative differences center around GZ, FS, and DG. The changes in surface $\mathrm{PM}_{2.5}$ concentration are obviously affected by meteorological elements. For example, the decrease in wind speed limits the transport of $\mathrm{PM}_{2.5}$. Besides, $\mathrm{PBLH}$ also plays an important role in $\mathrm{PM}_{2.5}$ concentration. The higher mixing layer caused by urban expansion is conducive to the vertical dispersion and dilution of $\mathrm{PM}_{2.5}$ within the boundary layer. More $\mathrm{PM}_{2.5}$ is transported into the upper air, and, thus, the $\mathrm{PM}_{2.5}$ concentration decreases near the surface but increases at higher altitudes due to the net influence of land-use change, as shown in Figures 9(c) and 9(d). It should be noted that the decrease in $\mathrm{PM}_{2.5}$ concentration during the nighttime was noticeably larger than that during the daytime. As the relative 


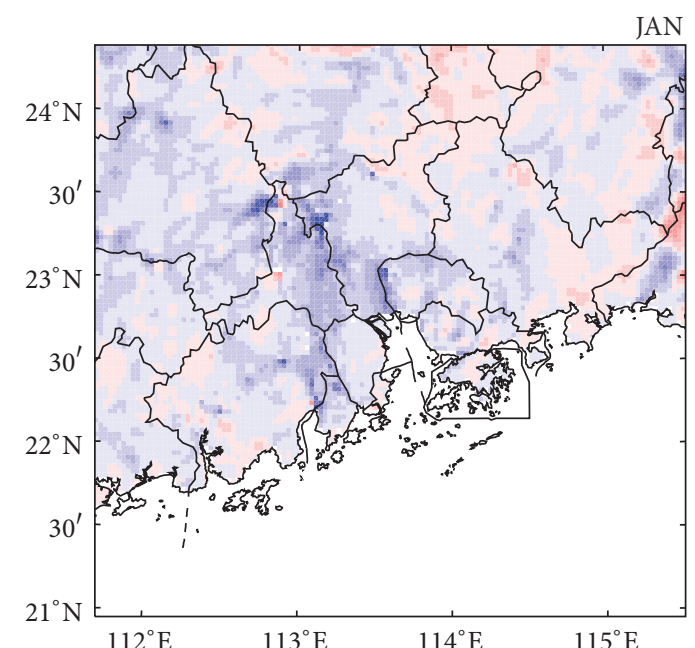

(a) Diff. of $\mathrm{PM}_{2.5}\left(\mu \mathrm{g} / \mathrm{m}^{3}\right)$

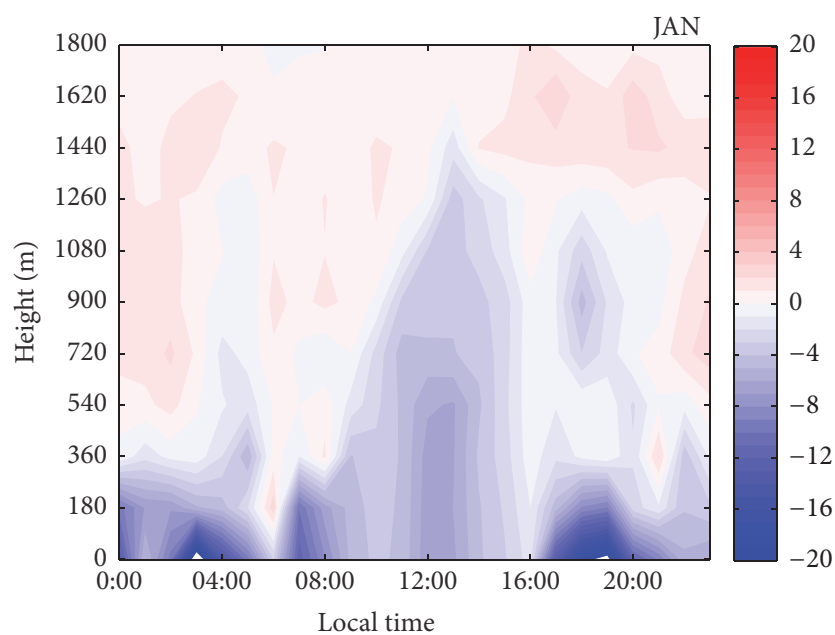

(c) Diff. of $\mathrm{PM}_{2.5}\left(\mu \mathrm{g} / \mathrm{m}^{3}\right)$

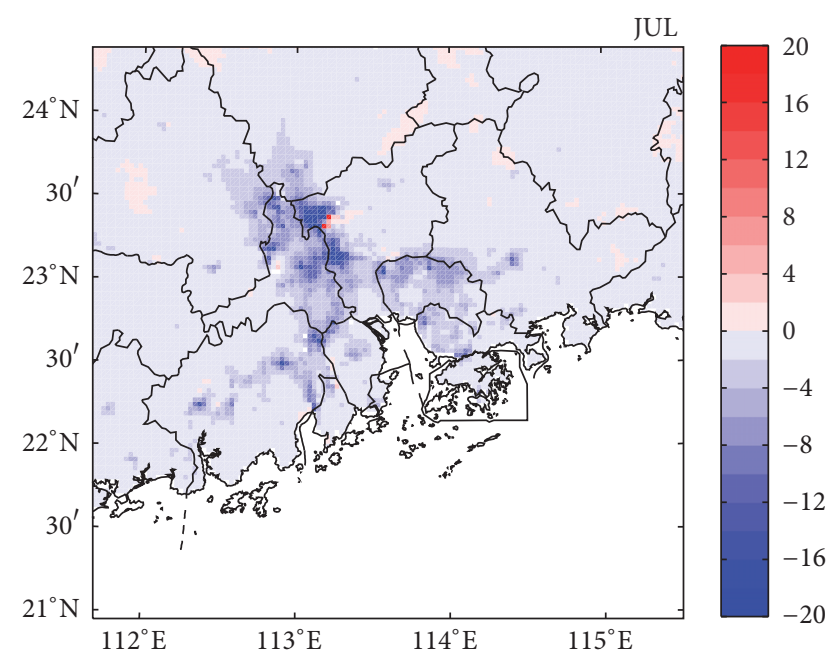

(b) Diff. of $\mathrm{PM}_{2.5}\left(\mu \mathrm{g} / \mathrm{m}^{3}\right)$

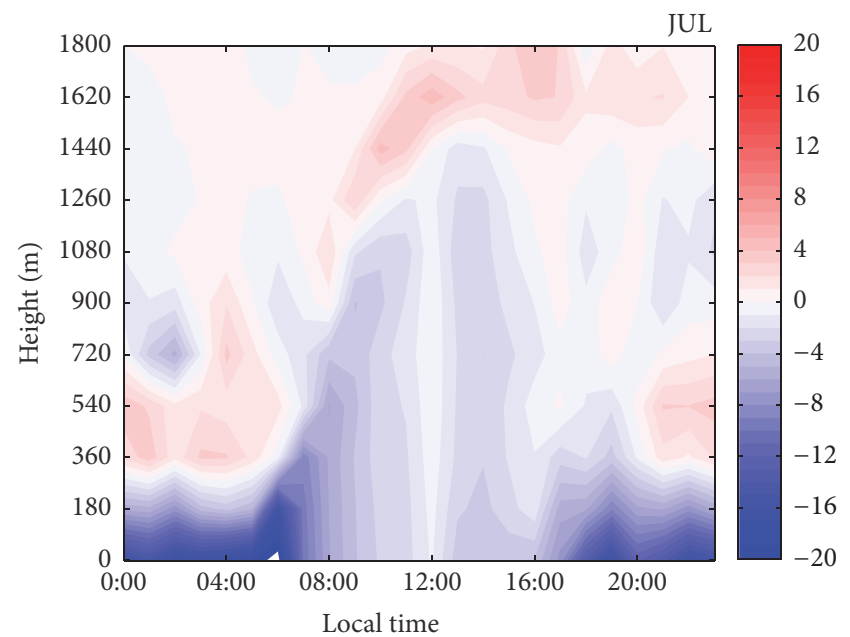

(d) Diff. of $\mathrm{PM}_{2.5}\left(\mu \mathrm{g} / \mathrm{m}^{3}\right)$

FIGURE 9: Spatial distribution of monthly-average $\mathrm{PM}_{2.5}$ concentration differences $\left(\mu \mathrm{g} / \mathrm{m}^{3}\right)(\mathrm{a}, \mathrm{b})$ and vertical distribution of $\mathrm{PM}_{2.5}$ differences $\left(\mu \mathrm{g} / \mathrm{m}^{3}\right)(\mathrm{c}, \mathrm{d})$ at GZ between the GLC2009 case and the GLC2000 case (differences = GLC2009 - GLC2000).

increase of nighttime PBLH was larger than that of daytime after land-use change, the enhancement of the diffusivity of $\mathrm{PM}_{2.5}$ was more noticeable during the nighttime, which further led to a larger decrease in $\mathrm{PM}_{2.5}$ concentration at night. Overall, the impact of land-use change on surface $\mathrm{PM}_{2.5}$ concentration is negative due to the altered dynamics and thermal processes.

The relative differences of surface $\mathrm{O}_{3}$ and $\mathrm{PM}_{2.5}$ concentrations due to land-use change in the nine cities of the PRD region are shown in Figure 10. Corresponding to Figure 2, the relative differences of pollutant concentrations in the areas with noticeable urban expansion, including GZ, FS, DG, and SZ, were significantly greater than those of the other five cities in the PRD region. Thus, atmospheric pollutants are sensitive to the change in land-use. Furthermore, a seasonal change is found in the simulations with larger relative differences of surface $\mathrm{O}_{3}$ and $\mathrm{PM}_{2.5}$ concentrations in July than those in January.

\section{Conclusions}

In this study, the WRF-Chem model was employed to investigate the impacts of land-use change on regional atmospheric environment in PRD region. Experiments with two land-use datasets were designed to represent the land cover conditions in the 2000s (referred to as the GLC2000 case) and 2010s (referred to as the GLC2009 case). Simulation periods were from 0000 UTC 30 December 2013 to 0000 UTC 01 February 2014 and from 0000 UTC 29 June to 0000 UTC 01 August 2014. Model verifications with observation data showed that the GLC2009 case reproduced meteorological and chemical conditions well with observations. The following conclusions can be drawn through comparative analysis of the GLC2009 case and the GLC2000 case:

(1) The modification of irrigated cropland into urban land results in significant changes of meteorological elements. The monthly-average $2 \mathrm{~m}$ temperature 


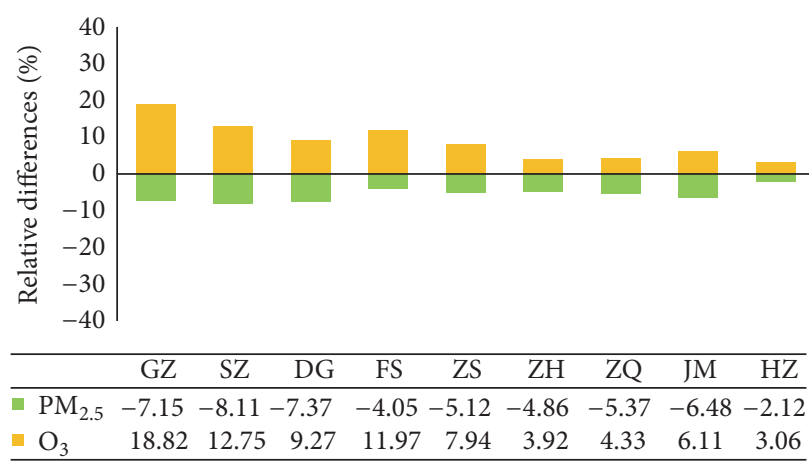

(a) January

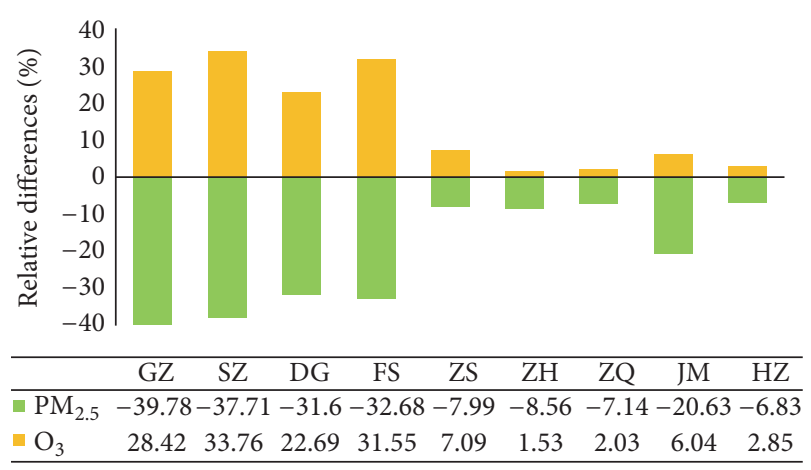

(b) July

FIGURE 10: Relative differences (\%) of $\mathrm{O}_{3}$ and $\mathrm{PM}_{2.5}$ between the GLC2009 case and the GLC2000 case in the nine cities of PRD.

in PRD region for January and July increased by $0.24^{\circ} \mathrm{C}$ and $0.27^{\circ} \mathrm{C}$, respectively, and nighttime temperatures increased more than daytime temperatures. Additionally, the urban dry island effect became noticeable, with the monthly-average $2 \mathrm{~m}$ water vapor content decreased by $0.07 \mathrm{~g} / \mathrm{kg}$ and $0.28 \mathrm{~g} / \mathrm{kg}$ and relative humidity decreased by $2.02 \%$ and $2.23 \%$ in January and July, respectively. Due to the increase of ground roughness, the monthly averaged $10 \mathrm{~m}$ wind direction changed and wind speed in January and July decreased by $0.19 \mathrm{~m} / \mathrm{s}$ and $0.16 \mathrm{~m} / \mathrm{s}$. The planetary boundary layer height increased throughout the day, with the relative increase being the largest during the nighttime. Regions along the Pearl River Estuary saw the significant changes of temperature, moisture, wind speed, and planetary boundary layer height due to their large urban expansion.

(2) Land-use change substantially influenced meteorological elements in $\mathrm{PRD}$ region, which, in turn, changed the distributions of $\mathrm{O}_{3}$ and $\mathrm{PM}_{2.5}$ concentration. Under the combined effects of higher temperature, decreased wind speed, and greater VOCs emission, the monthly averaged surface $\mathrm{O}_{3}$ concentration increased by $0.93 \mu \mathrm{g} / \mathrm{m}^{3}$ and $1.61 \mu \mathrm{g} / \mathrm{m}^{3}$ in January and July. Influenced by the strong mixing down of $\mathrm{O}_{3}$ in the residual layer and decreased $\mathrm{NO}_{x}$ concentration at night, the increase of the surface $\mathrm{O}_{3}$ concentration during the nighttime was larger than that during the daytime. The increase in the boundary layer height was conductive to vertical diffusion and dilution of pollutants, so the $\mathrm{PM}_{2.5}$ concentration decreased at the lower layer while it increased at the higher layer, and the monthly averaged surface $\mathrm{PM}_{2.5}$ concentration in January and July decreased by $1.58 \mu \mathrm{g} / \mathrm{m}^{3}$ and $3.76 \mu \mathrm{g} / \mathrm{m}^{3}$, respectively. Since the nighttime relative increase in the boundary layer height was larger than that for daytime, the decrease of the surface $\mathrm{PM}_{2.5}$ concentration at night was more obvious. Relative differences of pollutant concentration in the areas with noticeable urban expansion, including GZ, FS, DG, and SZ, were significantly greater than those of the other five cities in the PRD region. Furthermore, a seasonal change was found in the simulations with larger relative differences in surface $\mathrm{O}_{3}$ and $\mathrm{PM}_{2.5}$ concentrations in July than those in January.

(3) The results above indicate that the atmospheric environment is sensitive to land-use change, but further research is required concerning internal mechanisms. In addition to land-use change, changes in anthropogenic emissions, anthropogenic heat, and multiple canopy parameterizations due to urbanization are also important for the atmospheric environment and should be studied in the future.

\section{Competing Interests}

The authors declare that they have no competing interests.

\section{Acknowledgments}

This research was supported by funds from the China Special Fund for Meteorological Research in the Public Interest (GYHY201406031), the National Natural Science Foundation (91544102), the Science and Technology Planning Project of Guangdong Province, China (2014B020216003), and the Fundamental Research Funds for the Central Universities (15lgjc04). This work was also partly supported by the Jiangsu Collaborative Innovation Center for Climate Change and the high-performance grid-computing platform of Sun Yat-sen University.

\section{References}

[1] Y. Zhang, X.-Y. Wen, and C. J. Jang, "Simulating chemistryaerosol-cloud-radiation-climate feedbacks over the continental U.S. using the online-coupled Weather Research Forecasting Model with chemistry (WRF/Chem)," Atmospheric Environment, vol. 44, no. 29, pp. 3568-3582, 2010.

[2] W. Wang, "The influence of thermally-induced mesoscale circulations on turbulence statistics over an idealized urban area under a zero background wind," Boundary-Layer Meteorology, vol. 131, no. 3, pp. 403-423, 2009. 
[3] K. Civerolo, C. Hogrefe, B. Lynn et al., "Estimating the effects of increased urbanization on surface meteorology and ozone concentrations in the New York City metropolitan region," Atmospheric Environment, vol. 41, no. 9, pp. 1803-1818, 2007.

[4] M. Yu, G. R. Carmichael, T. Zhu, and Y. Cheng, "Sensitivity of predicted pollutant levels to urbanization in China," Atmospheric Environment, vol. 60, pp. 544-554, 2012.

[5] Z. Tao, J. A. Santanello, M. Chin et al., "Effect of land cover on atmospheric processes and air quality over the continental United States-a NASA Unified WRF (NU-WRF) model study," Atmospheric Chemistry and Physics, vol. 13, no. 13, pp. 62076226, 2013.

[6] X. Wang, F. Chen, Z. Wu et al., "Impacts of weather conditions modified by urban expansion on surface ozone: comparison between the Pearl River Delta and Yangtze River Delta regions, China," Advances in Atmospheric Sciences, vol. 26, no. 5, pp. $962-$ 972, 2009.

[7] Y. Fu and A. P. K. Tai, "Impact of climate and land cover changes on tropospheric ozone air quality and public health in East Asia between 1980 and 2010," Atmospheric Chemistry and Physics, vol. 15, no. 17, pp. 10093-10106, 2015.

[8] Y.-H. Ryu, J.-J. Baik, K.-H. Kwak, S. Kim, and N. Moon, "Impacts of urban land-surface forcing on ozone air quality in the Seoul metropolitan area," Atmospheric Chemistry and Physics, vol. 13, no. 4, pp. 2177-2194, 2013.

[9] Q. Weng, "Land use change analysis in the Zhujiang Delta of China using satellite remote sensing, GIS and stochastic modelling," Journal of Environmental Management, vol. 64, no. 3, pp. 273-284, 2002.

[10] W. S. Lin, C.-H. Sui, L. M. Yang et al., "A numerical study of the influence of urban expansion on monthly climate in dry autumn over the Pearl River Delta, China," Theoretical and Applied Climatology, vol. 89, no. 1-2, pp. 63-72, 2007.

[11] C. K. M. Cheng and J. C. L. Chan, "Impacts of land use changes and synoptic forcing on the seasonal climate over the Pearl River Delta of China," Atmospheric Environment, vol. 60, no. 6, pp. 2536, 2012.

[12] M. M. Li, Y. Song, Z. C. Mao, M. Liu, and X. Huang, "Impacts of thermal circulations induced by urbanization on ozone formation in the Pearl River Delta region, China," Atmospheric Environment, vol. 127, pp. 382-392, 2016.

[13] X. M. Wang, Z. Y. Wu, and G. X. Liang, "WRF/CHEM modeling of impacts of weather conditions modified by urban expansion on secondary organic aerosol formation over Pearl River Delta," Particuology, vol. 7, no. 5, pp. 384-391, 2009.

[14] M. Li, Y. Song, X. Huang et al., "Improving mesoscale modeling using satellite-derived land surface parameters in the Pearl River Delta region, China," Journal of Geophysical Research Atmospheres, vol. 119, no. 11, pp. 6325-6346, 2014.

[15] X. Wang, F. Chen, Z. Wu et al., "Impacts of weather conditions modified by urban expansion on surface ozone: comparison between the Pearl River Delta and Yangtze River Delta regions," Advances in Atmospheric Sciences, vol. 26, no. 5, pp. 962-972, 2009.

[16] M. Chang, S. Fan, Q. Fan et al., "Impact of refined land surface properties on the simulation of a heavy convective rainfall process in the Pearl River Delta region, China," Asia-Pacific Journal of Atmospheric Sciences, vol. 50, no. 1, pp. 645-655, 2014.

[17] Y. Zhang, "Online-coupled meteorology and chemistry models: history, current status, and outlook," Atmospheric Chemistry and Physics, vol. 8, no. 11, pp. 2895-2932, 2008.
[18] X. Tie, S. Madronich, G. Li et al., "Characterizations of chemical oxidants in Mexico City: a regional chemical dynamical model (WRF-Chem) study," Atmospheric Environment, vol. 41, no. 9, pp. 1989-2008, 2007.

[19] L. Li, C. H. Chen, J. S. Fu et al., "Air quality and emissions in the Yangtze River Delta, China," Atmospheric Chemistry and Physics, vol. 11, no. 4, pp. 1621-1639, 2011.

[20] F. Jiang, T. J. Wang, T. T. Wang, M. Xie, and H. Zhao, "Numerical modeling of a continuous photochemical pollution episode in Hong Kong using WRF-chem," Atmospheric Environment, vol. 42, no. 38, pp. 8717-8727, 2008.

[21] Y.-L. Lin, R. D. Farley, and H. D. Orville, "Bulk parameterization of the Snow field in a cloud model," Journal of Climate and Applied Meteorology, vol. 22, no. 6, pp. 1065-1092, 1983.

[22] E. J. Mlawer, S. J. Taubman, P. D. Brown, M. J. Iacono, and S. A. Clough, "Radiative transfer for inhomogeneous atmospheres: RRTM, a validated correlated-k model for the longwave," Journal of Geophysical Research D: Atmospheres, vol. 102, no. 14, pp. 16663-16682, 1997.

[23] H.-J. Kim and B. Wang, "Sensitivity of the WRF model simulation of the East Asian summer monsoon in 1993 to shortwave radiation schemes and ozone absorption," Asia-Pacific Journal of Atmospheric Sciences, vol. 47, no. 2, pp. 167-180, 2011.

[24] Y. Noh, W. G. Cheon, S. Y. Hong, and S. Raasch, "Improvement of the K-profile model for the planetary boundary layer based on large eddy simulation data," Boundary-Layer Meteorology, vol. 107, no. 2, pp. 401-427, 2003.

[25] F. Chen and J. Dudhia, "Coupling and advanced land surfacehydrology model with the Penn State-NCAR MM5 modeling system - part I: model implementation and sensitivity," Monthly Weather Review, vol. 129, no. 4, pp. 569-585, 2001.

[26] R. A. Zaveri and L. K. Peters, "A new lumped structure photochemical mechanism for large-scale applications," Journal of Geophysical Research: Atmospheres, vol. 104, no. 23, pp. 30387-30415, 1999.

[27] R. A. Zaveri, R. C. Easter, J. D. Fast, and L. K. Peters, "Model for simulating aerosol interactions and chemistry (MOSAIC)," Journal of Geophysical Research Atmospheres, vol. 113, no. 13, pp. 1395-1400, 2008.

[28] J. Zheng, L. Zhang, W. Che, Z. Zheng, and S. Yin, "A highly resolved temporal and spatial air pollutant emission inventory for the Pearl River Delta region, China and its uncertainty assessment," Atmospheric Environment, vol. 43, no. 32, pp. 51125122, 2009.

[29] A. Guenther, T. Karl, P. Harley, C. Wiedinmyer, P. I. Palmer, and C. Geron, "Estimates of global terrestrial isoprene emissions using MEGAN (Model of Emissions of Gases and Aerosols from Nature)," Atmospheric Chemistry and Physics, vol. 6, no. 11, pp. 3181-3210, 2006.

[30] E. Bartholomé and A. S. Belward, "GLC2000: a new approach to global land cover mapping from earth observation data," International Journal of Remote Sensing, vol. 26, no. 9, pp. 19591977, 2005.

[31] O. Arino, P. Bicheron, F. Achard et al., "GlobCover: the most detailed portrait of Earth," Esa Bulletin-European Space Agency, vol. 136, pp. 24-31, 2008.

[32] L. J. M. Jansen and A. D. Gregorio, Land Cover Classification System (LCCS): Classification Concepts and User Manual, 2000.

[33] L. Fei and C. G. Gong, "Accuracy evaluation of globe land cover products GLC2009 in typical regions in China," Journal of Heilongjiang University of Science \& Technology, vol. 24, no. 6, pp. 658-662, 2014 (Chinese). 
[34] Y. Ran, X. Li, and L. Lu, "Evaluation of four remote sensing based land cover products over China," International Journal of Remote Sensing, vol. 31, no. 2, pp. 391-401, 2010.

[35] W. Wu, R. Shibasaki, P. Yang, L. Ongaro, Q. Zhou, and H. Tang, "Validation and comparison of $1 \mathrm{~km}$ global land cover products in China," International Journal of Remote Sensing, vol. 29, no. 13, pp. 3769-3785, 2008.

[36] F. Chen, "The Noah Land Surface Model in WRF: A short tutorial," LSM group meeting, April 2007.

[37] N. Zhang, Z. Gao, X. Wang, and Y. Chen, "Modeling the impact of urbanization on the local and regional climate in Yangtze River Delta, China," Theoretical \& Applied Climatology, vol. 102, no. 3, pp. 331-342, 2010.

[38] J. Liao, T. Wang, Z. Jiang et al., "WRF/Chem modeling of the impacts of urban expansion on regional climate and air pollutants in Yangtze River Delta, China," Atmospheric Environment, vol. 106, pp. 204-214, 2015.

[39] J. Aw and M. J. Kleeman, "Evaluating the first-order effect of intraannual temperature variability on urban air pollution," Journal of Geophysical Research Atmospheres, vol. 108, no. 12, pp. 975-984, 2003.

[40] H. Taha, "Urban surface modification as a potential ozone air-quality improvement strategy in California: a mesoscale modelling study," Boundary-Layer Meteorology, vol. 127, no. 2, pp. 219-239, 2008.

[41] S. Sillman and P. J. Samson, "Impact of temperature on oxidant photochemistry in urban, polluted rural and remote environments," Journal of Geophysical Research, vol. 100, no. 6, pp. 11497-11508, 1995.

[42] N. Baertsch-Ritter, J. Keller, J. Dommen, and A. S. H. Prevot, "Effects of various meteorological conditions and spatial emission resolutions on the ozone concentration and ROG/NOx limitation in the Milan area (I)," Atmospheric Chemistry and Physics, vol. 4, no. 2, pp. 423-438, 2004.

[43] M. Shao, Y. Zhang, L. Zeng et al., "Ground-level ozone in the Pearl River Delta and the roles of VOC and NOx in its production," Journal of Environmental Management, vol. 90, no. 1, pp. 512-518, 2009. 

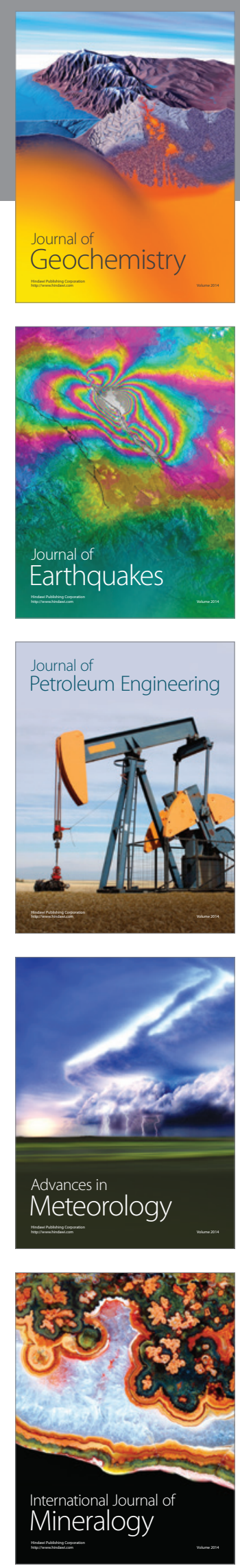
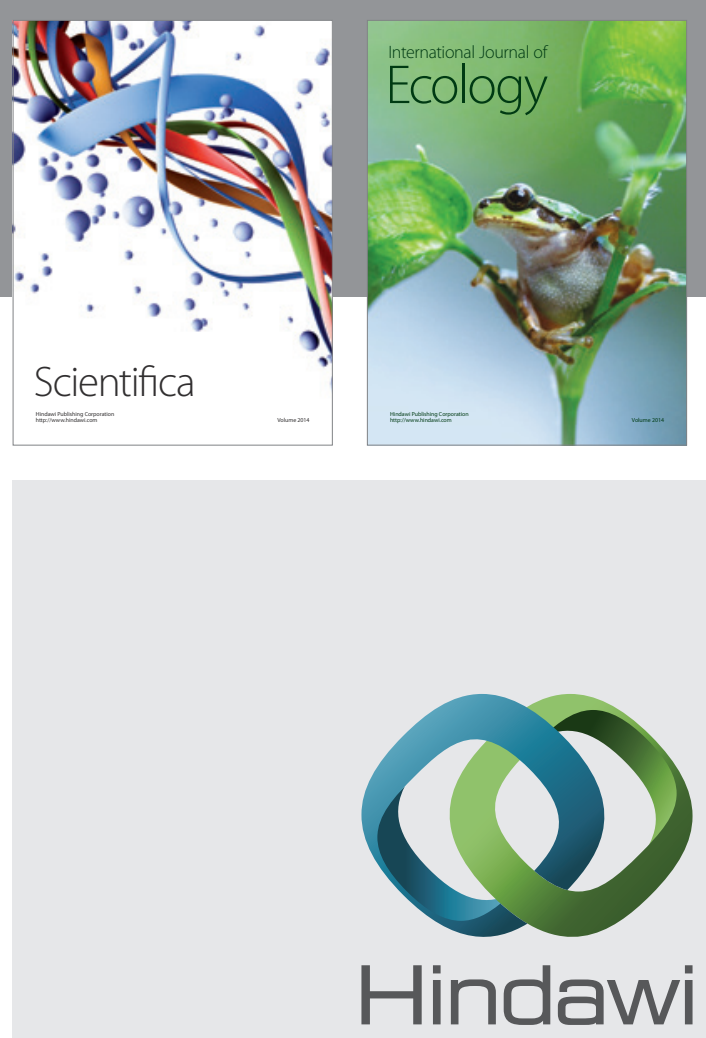

Submit your manuscripts at

http://www.hindawi.com
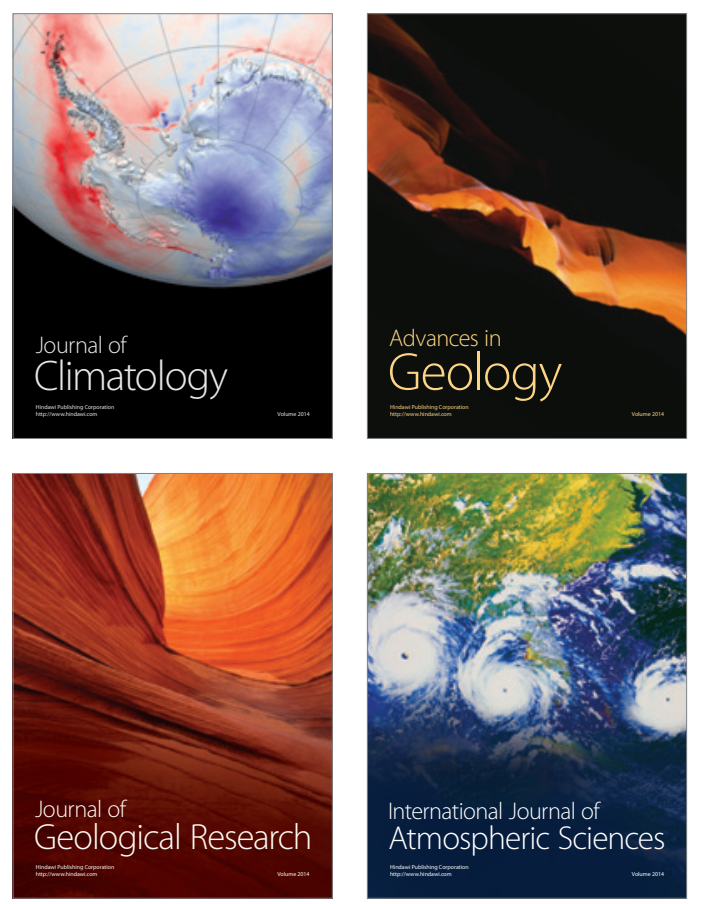

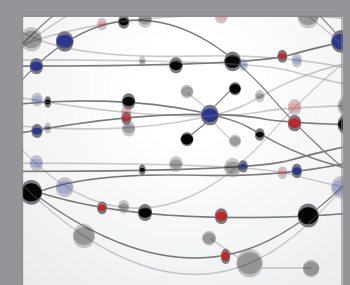

The Scientific

\section{World Journal}
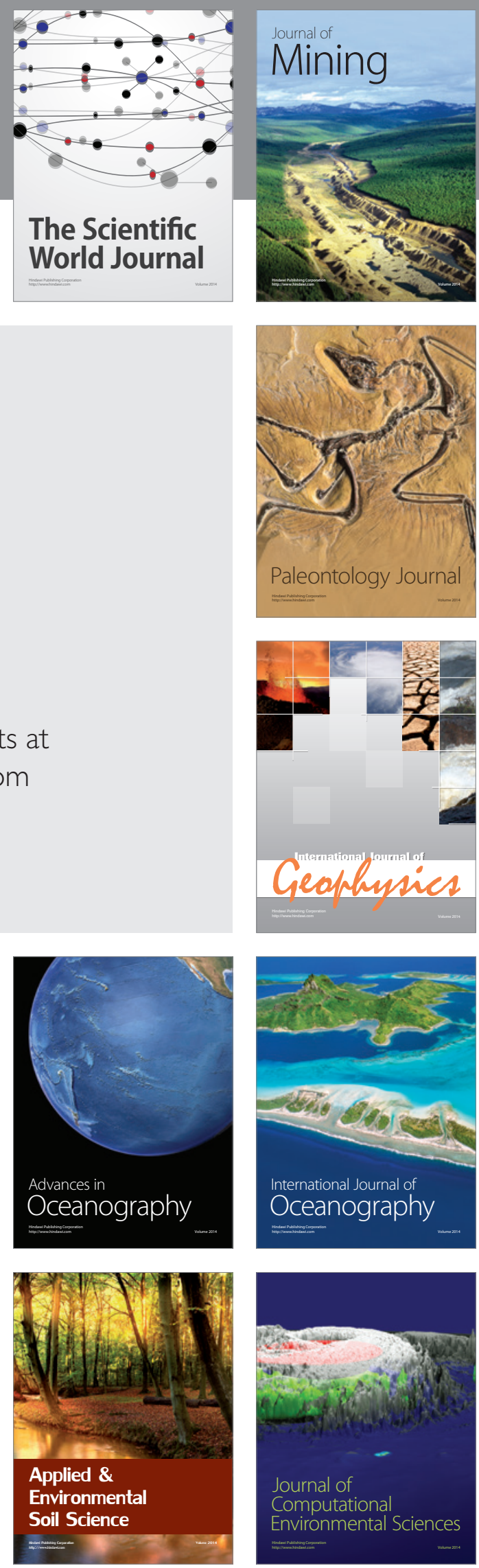